\title{
Extension of the Averaging Time in Eddy-Covariance Measurements and Its Effect on the Energy Balance Closure
}

\author{
Doojdao Charuchittipan · Wolfgang Babel • Matthias Mauder • \\ Jens-Peter Leps • Thomas Foken
}

Received: 25 February 2013 / Accepted: 10 March 2014 / Published online: 12 April 2014

(C) The Author(s) 2014. This article is published with open access at Springerlink.com

\begin{abstract}
The modified ogive analysis and the block ensemble average were employed to investigate the impact of the averaging time extension on the energy balance closure over six land-use types. The modified ogive analysis, which requires a steady-state condition, can extend the averaging time up to a few hours and suggests that an averaging time of $30 \mathrm{~min}$ is still overall sufficient for eddy-covariance measurements over low vegetation. The block ensemble average, which does not require a steady-state condition, can extend the averaging time to several days. However, it can improve the energy balance closure for some sites during specific periods, when secondary circulations exist in the vicinity of the sensor. These nearsurface secondary circulations mainly transport sensible heat, and when near-ground warm air is transported upward, the sensible heat flux observed by the block ensemble average will increase at longer averaging times. These findings suggest an alternative energy balance correction for a ground-based eddy-covariance measurement, in which the attribution of the residual depends on the ratio of sensible heat flux to the buoyancy flux. The fraction of the
\end{abstract}

D. Charuchittipan $(\varangle) \cdot$ W. Babel · T. Foken

Department of Micrometeorology, University of Bayreuth, 95440 Bayreuth, Germany

e-mail: doojdao@su.ac.th

Present Address

D. Charuchittipan

Department of Physics, Faculty of Science, Silpakorn University,

73000 Nakorn Pathom, Thailand

M. Mauder

Institute of Meteorology and Climate Research, Karlsruhe Institute of Technology,

82467 Garmisch-Partenkirchen, Germany

J.-P. Leps

German Meteorological Service, Richard-Aßmann-Observatory, 15848 Lindenberg, Germany

T. Foken

Bayreuth Center of Ecology and Environmental Research (BayCEER),

University of Bayreuth, Bayreuth, Germany 
residual attributed to the sensible heat flux by this energy balance correction is larger than in the energy balance correction that preserves the Bowen ratio.

Keywords Energy balance closure $\cdot$ Ensemble average $\cdot$ LITFASS · Ogive analysis

\section{Introduction}

The imbalance of the measured fluxes at the earth's surface is known as the energy balance closure problem and micrometeorologists have been aware of it since the late 1980s (Foken 2008a; Leuning et al. 2012). Many micrometeorological experiments over low vegetation reveal that the available energy, which is the sum of the net radiation and the ground heat flux, is larger than the sum of the sensible and latent heat fluxes. These experiments include the EBEX experiment (EBEX, 'Energy Balance Experiment', Oncley et al. 2007), which was especially designed to study the energy balance at the earth's surface, and the LITFASS-2003 experiment (LITFASS, 'Lindenberg Inhomogeneous Terrain - Fluxes between Atmosphere and Surface: a long-term Study', Beyrich and Mengelkamp 2006), which aimed to study the effect of surface heterogeneity. To conserve energy, the residual was added to the energy budget equation over low vegetation at the earth's surface, in which for the stationary and horizontally homogeneous surface layer,

$$
R e s=-Q^{*}-\left(Q_{\mathrm{G}}+Q_{\mathrm{H}}+Q_{\mathrm{E}}\right),
$$

where Res is the residual or missing energy, $Q^{*}$ is the net radiation, $Q_{\mathrm{G}}$ is the ground heat flux, $Q_{\mathrm{H}}$ is the sensible heat flux, and $Q_{\mathrm{E}}$ is the latent heat flux. Each term in Eq. 1 is positive, as the energy is transported away from the ground.

In the past few years, despite improvements in measuring and data processing techniques (see review in Foken 2008a; Foken et al. 2011), the energy balance closure problem still remains. According to several studies using large-eddy simulation (LES), the energy balance is significantly improved with contributions from secondary circulations or turbulent organized structures (Kanda et al. 2004; Inagaki et al. 2006; Steinfeld et al. 2007). These secondary circulations are large-scale eddies (several $\mathrm{km}$ ) and relatively stationary (either static or move very slowly). They are generated by surface heterogeneity (Stoy et al. 2013) and normally move away from the ground. Due to their large size and slow motion, their contributions to the low frequency part of the turbulent spectrum cannot be detected by the eddy-covariance (EC) measurement, which is typically averaged over a period of $30 \mathrm{~min}$. This results in the underestimation of $Q_{\mathrm{H}}$ and $Q_{\mathrm{E}}$, when normally measured by the EC technique.

An extension of the averaging time was suggested and expected to result in a greater contribution from the low frequency parts. Two different approaches were introduced for this task: the ogive analysis (Desjardins et al. 1989; Oncley et al. 1990) and the block ensemble average (Bernstein 1966, 1970; Finnigan et al. 2003). The ogive analysis, which requires a steady-state condition, uses the turbulent spectrum to estimate the turbulent fluxes for different frequency ranges, allowing assessment of the contribution of the low frequencies to the turbulent fluxes measured by the EC method. In Foken et al. (2006), the ogive analysis was applied to the data measured over a maize field of the LITFASS-2003 experiment and was focused mainly on data from three selected days, where the averaging time was extended up to $4 \mathrm{~h}$. It was found that the time extension did not significantly increase the turbulent fluxes overall. 
For the block ensemble average, which does not require a steady-state condition, low frequency contributions were added to the turbulent fluxes from long-term fluctuations over several hours to days. Detailed discussion of the block ensemble average can be found in Aubinet et al. (2012). In Mauder and Foken (2006), the block ensemble average was also applied to the dataset from the same maize field of the LITFASS-2003 experiment. The length of the selected dataset was 15 days, while the block ensemble averaging period varied from 5 min to 5 days. This study showed that the block ensemble average can close the energy balance at longer averaging times. Extensive discussion of the energy balance closure of the LITFASS-2003 experiment can be found in Foken et al. (2010).

In our study, we applied both ogive analysis and block ensemble average to the data from the LITFASS-2003 experiment, which was collected by multiple EC towers over a large heterogeneous area. This surface heterogeneity may induce secondary circulations, some of which may still exist in the vicinity of the measuring stations and influence the measured fluxes. We examine the impact of averaging time extension over different types of surface that were broadly exposed to the same atmospheric condition. However, the data obtained from different measuring stations do not always have the same sampling rate, thus minor modifications in both ogive analysis and block ensemble average were made. These modifications were validated by repeating the ogive analysis in Foken et al. (2006) and the block ensemble average in Mauder and Foken (2006). Since the energy balance of this dataset was previously analyzed over $30 \mathrm{~min}$ (Beyrich et al. 2006; Foken et al. 2010), we could mainly concentrate on the averaging time beyond $30 \mathrm{~min}$, which is more related to the low frequency contributions.

\section{Material and Method}

\subsection{LITFASS-2003 Experiment and Data Processing}

The LITFASS-2003 experiment was performed between 19 May 2003 and 18 June 2003 near the Richard-Aßmann-Observatory of the German Meteorological Service in Lindenberg, Germany. The local time zone in this area is UTC +1 . During the experiment, there were 14 ground-based micrometeorological measuring stations over 13 sites, and two elevated measuring stations on the tower at 50 and $90 \mathrm{~m}$ heights. This experiment covered an area of $20 \times 20 \mathrm{~km}^{2}$ and made up of six major land-use types: grass, maize, rape, cereals (include rye, barley and triticale), lake and forest. More information about the LITFASS-2003 experiment can be found in Beyrich and Mengelkamp (2006).

To cover the most important land-use types for the LITFASS-2003 experiment, we selected the following measuring stations for our study: grass (NV2 and NV4), maize (A6), rape (A7), rye (A5), lake (FS) and forest (HV). Note that NV2 and NV4 were actually installed on the same field, and were oriented to different wind sectors to monitor turbulence at this field from all wind directions. We combined these two stations according to the wind direction and they were reported as the single station NV. Information of these selected stations can be found in Table 1 .

All selected stations were equipped with EC systems as listed in Table 1. Four-component net radiometers and soil heat flux plates were also installed, therefore all the energy balance components in Eq. 1 were measured at each station. Details of these measurements were well described in Mauder et al. (2006) and Liebethal et al. (2005). These measurements allow estimation of the residual, which, on average, reached its maximum at 1000-1200 
Table 1 Summary of selected measuring stations from the LITFASS-2003 experiment during 20 May 2003, 1200 UTC-18 June 2003, 0000 UTC

\begin{tabular}{lllllllll}
\hline Station & Canopy & $h_{\mathrm{c}}(\mathrm{m})$ & $z_{\mathrm{m}}(\mathrm{m})$ & $\theta\left(^{\circ}\right)$ & Turbulence sensors & $\Delta t(\mathrm{~min})$ & $\operatorname{Res}\left(\mathrm{W} \mathrm{m}^{-2}\right)$ & $\% \operatorname{Res}(\%)$ \\
\hline HV & Pine forest & 14 & 30.5 & $30-330$ & USA-1/LI-7500 & 10 & 133 & 24 \\
A5 & Rye & $0.75-1.50$ & 2.8 & $60-30$ & USA-1/KH20 & 5 & 144 & 30 \\
A6 & Maize & $0.05-0.70$ & 2.7 & $90-270$ & CSAT3/LI-7500 & 5 & 122 & 31 \\
A7 & Rape & $0.70-0.90$ & 3.4 & $30-240$ & CSAT3/KH20 & 5 & 87 & 22 \\
NV2 & Grass & $0.05-0.25$ & 2.4 & $60-180$ & USA-1/LI-7500 & 5 & 75 & 22 \\
NV4 & Grass & $0.05-0.25$ & 2.4 & $150-330$ & USA-1/LI-7500 & 5 & 82 & 24 \\
FS & Lake & 0 & 3.9 & $180-30$ & USA-1/LI-7500 & 10 & - & - \\
M50 & Grass & $0.05-0.25$ & 50.7 & $90-300$ & USA-1/LI-7500 & 5 & - & - \\
M90 & Grass & $0.05-0.25$ & 90.7 & $90-300$ & USA-1/LI-7500 & 5 & - & - \\
\hline
\end{tabular}

Full details can be found in Beyrich and Mengelkamp (2006) and Mauder et al. (2006)

$h_{\mathrm{c}}$ canopy height, $z_{\mathrm{m}}$ measurement height, $\theta$ accepted wind direction, $\Delta t$ timestep of short-term time series, Res mean residual between 1000-1200 UTC, this is when the residual is normally reach its maximum; $\%$ Res $=100$ Res $/\left(-Q^{*}-Q_{\mathrm{G}}\right)$ between $1000-1200 \mathrm{UTC}$

Note that Res was calculated from Eq. 1, which does not include the canopy heat storage term

UTC. For low vegetation, its average value during this time ranged from 75 to $145 \mathrm{~W} \mathrm{~m}^{-2}$ (or 20-30\% of the available energy as shown in Table 1).

All kinds of plants store energy in their canopies. This canopy heat storage has two main contributions from the plant material (or biomass) and the air between plants. In Oncley et al. (2007), it was shown that over low vegetation, such as a cotton field, both contributions of canopy heat storage are relatively small and negligible. According to the study in maize and soybean (Meyers and Hollinger 2004), the stored energy in biomass is significant when a canopy is fully developed, while $Q_{\mathrm{G}}$ is very low. During the LITFASS-2003 experiment, the maize field grew from bare soil up to approximately $0.5 \mathrm{~m}$ height at the end of the experiment. Therefore, the stored energy in biomass can be neglected in our analyses. However, a forest's canopy heat storage is significant (Lindroth et al. 2010) and needs to be included in the energy budget equation (Eq. 1). Unfortunately, we did not collect all required biomass properties of the forest during the LITFASS-2003 experiment, so a forest's canopy heat storage could not be precisely estimated. Hence, all analyses of this site were done without a canopy heat storage term. Since a forest's canopy heat storage during the daytime would release heat back to the atmosphere during the nighttime, it is more important at the sub-diurnal scale (Haverd et al. 2007). Therefore, the omission of a forest's canopy heat storage would have a minimal effect over a long-term basis. For the lake, due to its characteristics (e.g. large heat capacity), its energy budget cannot be described by Eq. 1. Therefore, its residual is not reported in Table 1 .

During the LITFASS-2003 campaign, the raw data were processed and averaged over $30 \mathrm{~min}$. For this task, all the participating groups agreed to use the software package TK2 (Mauder and Foken 2004), which has been tested and compared internationally (Mauder et al. 2008). During flux calculation, several corrections were applied. Cross-correlation analysis was used for fixing the time delay between the sonic anemometer and hygrometer, and a correction was used for the spectral loss in the high frequency range (Moore 1986). The planar-fit rotation was used to align the sonic anemometer with a long-term mean streamline (Wilczak et al. 2001); a correction was used to convert the sonic temperature, as recorded by the sonic anemometer, to the actual temperature (Schotanus et al. 1983); a correction was used to correct for density fluctuation (Webb et al. 1980). Crosswind correction was used to 
account for a different type of sonic anemometer (Liu et al. 2001), and a correction was used for the cross sensitivity between $\mathrm{H}_{2} \mathrm{O}$ and $\mathrm{O}_{2}$ molecules (Tanner et al. 1993), which was only applied for the Krypton hygrometer KH20 (deployed in A5 and A7). More details of these corrections can be found in Mauder et al. (2006) and Foken et al. (2012).

After all flux corrections, quality flags were assigned to each 30 -min period. These quality flags are the steady-state flag, the integral turbulence characteristic (ITC) flag (Foken and Wichura 1996) and combined flag. The steady-state flag is a result of the steady-state test and represents the stationarity of the data. The ITC flag represents the development of turbulent conditions, which is the result of the flux variance similarity test. The combined flag is the combination of the steady-state and ITC flags. All these flags range from 1 to 9 (from best to worst). High quality data, considered suitable for fundamental scientific research, have flag values of 1-3. More details of the data quality analysis can be found in Foken et al. (2004, 2012).

Besides flux calculations, flux corrections and assignment of data quality flags, the package TK2 can also generate short-term averages and covariances at 5-min or 10-min intervals. Due to the limited storage capacity, these short-term average data points were stored instead of the raw data from several measuring stations. However, the statistics for longer periods can be reconstructed from this short-term information with the following (Foken 2008b),

$$
\overline{a^{\prime} b^{\prime}}=\frac{1}{M-1}\left[(U-1) \sum_{j=1}^{N}\left(\overline{a^{\prime} b^{\prime}}\right)_{j}+U \sum_{j=1}^{N} \bar{a}_{j} \bar{b}_{j}-\frac{U^{2}}{M-1} \sum_{j=1}^{N} \bar{a}_{j} \sum_{j=1}^{N} \bar{b}_{j}\right],
$$

where $\overline{a^{\prime} b^{\prime}}$ is the long-term covariance and $M$ is the number of measurement points of the long-term time series. This long-term time series consists of $N$ short-term time series, whose number of measurement points is $U ;\left(\overline{a^{\prime} b^{\prime}}\right)_{j}$ is the short-term covariance, and $\bar{a}_{j}$ and $\bar{b}_{j}$ are the short-term averages. These short-term averages are derived from raw data, to which no flux correction has been applied. Therefore, any necessary flux corrections must be included when using these short-term averages for flux calculations. These short-term average data points from selected stations were used for both ogive analysis and block ensemble average calculations. Short-term averaging intervals of selected stations are shown in Table 1.

\subsection{Data Selection}

In most selected measuring stations, ground heat flux and radiation data are only available from 20 May 2003, 1200 UTC, so the period 20 May 2003, 1200 UTC-18 June 2003, 0000 UTC was used in our study. To ensure high data quality, as well as to minimize the irrelevant factors that might influence turbulent fluxes, we imposed sets of data selection criteria to the ogive analysis and block ensemble average separately. For the ogive analysis, we increased the averaging time to up to $4 \mathrm{~h}$. This 4 -h period consists of eight consecutive subperiods (or blocks) of $30 \mathrm{~min}$. We performed the ogive analysis over any 4-h period only if all blocks satisfied the selection criteria.

The first selection criterion is identical to Mauder et al. (2006), which is that the sonic anemometers must not be disturbed by either the internal boundary layer resulting from the heterogeneity of the surface, or the flow distortion caused by obstacles. The internal boundary-layer height was estimated from

$$
z_{\mathrm{m}} \leq \delta=0.3 \sqrt{x}
$$


(Raabe 1983) where $z_{\mathrm{m}}$ is the measurement height, $\delta$ is the internal boundary-layer height and $x$ is the distance from the sensor to boundary of the next land-use class. To keep the measurement undisturbed, $z_{\mathrm{m}}$ must not exceed $\delta$. Hence, we rejected any wind direction whose corresponding $x$ did not satisfy Eq. 3. The undisturbed wind sectors $(\theta)$ of each measuring station, from both internal boundary layer and flow distortion, are listed in Table 1. Additionally, footprint analysis was used to confirm that the target land-use type has a significant contribution to our measurement. This contribution varied over the stability range. We further rejected any wind sectors whose contribution from target land-use type is less than $80 \%$.

The next data selection criterion is a steady-state condition of the time series, which is indicated by the steady-state flag (Sect. 2.1). We only accepted data with high quality flags (flag 1-3). In this study, we did the ogive analysis of the energy balance components $\left(Q_{\mathrm{H}}\right.$ and $\left.Q_{\mathrm{E}}\right)$ and $\mathrm{CO}_{2}$ flux $\left(F_{\mathrm{c}}=\overline{w^{\prime} c^{\prime}} \mathrm{CO}_{2}\right)$ separately. For the energy balance components, we only considered the steady-state flags of friction velocity $\left(u_{*}\right), Q_{\mathrm{H}}$ and $Q_{\mathrm{E}}$. We only performed the ogive analysis on any periods during which these three steady-state flags qualified simultaneously. For $F_{\mathrm{c}}$, we considered only steady-state flags of $u_{*}$ and $\mathrm{CO}_{2}$ flux, and performed the ogive analysis on any periods where these two steady-state flags were accepted simultaneously.

We avoided the transition period by excluding from our analysis the time period covering one hour before to one hour after both sunrise and sunset. We also specified the threshold value of each turbulent flux as a minimum requirement in our analysis. For $u_{*}$, which indicates the intensity of turbulence (Massman and Lee 2002), the threshold value is $0.1 \mathrm{~m} \mathrm{~s}^{-1}$; this was set to rule out very small turbulent fluxes, which can result from instrumentation noise. This limit normally excludes periods with very weak flow as well. For $Q_{\mathrm{H}}, Q_{\mathrm{E}}$ and $F_{\mathrm{c}}$, threshold values were formulated to avoid complication with their measurement errors. According to Mauder et al. (2006), based on a 30-min averaging time, the measurement errors of $Q_{\mathrm{H}}$ and $Q_{\mathrm{E}}$ are $10-20 \%$ of the turbulent flux at $30 \mathrm{~min}$, or $10-20 \mathrm{~W} \mathrm{~m}^{-2}$, whichever is larger. For $u_{*}$ and $F_{\mathrm{c}}$, the measurement errors are $0.02-0.04 \mathrm{~m} \mathrm{~s}^{-1}$ and $0.5-1 \mu \mathrm{mol} \mathrm{m}^{-2} \mathrm{~s}^{-1}$, respectively (Meek et al. 2005). Therefore, we set the threshold values of $Q_{\mathrm{H}}$ and $Q_{\mathrm{E}}$ to be $20 \mathrm{~W} \mathrm{~m}^{-2}$, and the threshold value of $F_{\mathrm{c}}$ to be $1 \mu \mathrm{mol} \mathrm{m} \mathrm{m}^{-2} \mathrm{~s}^{-1}$. Unusually large uncertainty of $F_{\mathrm{c}}$ during the nighttime was taken into account by using only data periods with $u_{*}>0.25 \mathrm{~m}$ $\mathrm{s}^{-1}$ (Hollinger and Richardson 2005).

Similar selection criteria cannot apply to the block ensemble average, as this involves averaging times of several hours to days. Therefore, the quality control of this part was done by discarding any periods with more than $10 \%$ of missing raw data. This missing data could result from various factors, e.g. electrical failure.

\subsection{Modified Ogive Analysis}

The ogive analysis was introduced by Desjardins et al. (1989) and Oncley et al. (1990) to investigate the flux contribution from each frequency range as well as to determine suitable averaging periods to capture most of the turbulent fluxes. The ogive function of the turbulent flux $\left(\operatorname{og}_{w, c}\right)$ is defined as the cumulative integral of the cospectrum of the turbulent flux $\left(C o_{w, c}\right)$ starting with the highest frequency,

$$
\operatorname{og}_{w, c}\left(f_{0}\right)=\int_{\infty}^{f_{0}} C o_{w, c}(f) \mathrm{d} f,
$$




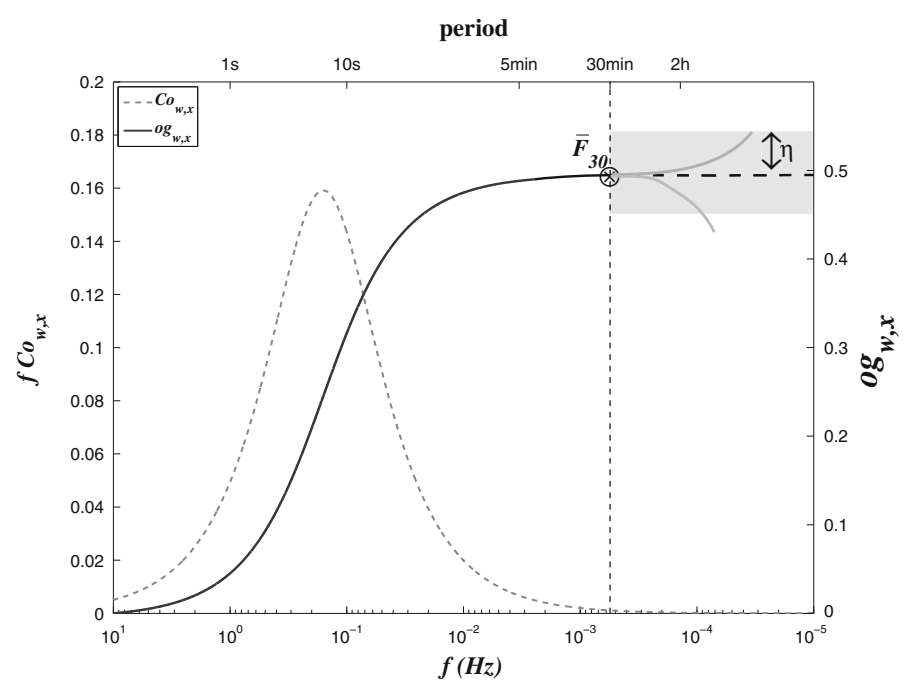

Fig. 1 The short-term average time series can estimate the turbulent flux at a 30-min period $\left(\bar{F}_{30}\right)$ and its evolution after that (grey solid lines in a grey band). The error band of width $2 \eta$ (grey band) was defined for identifying the ogive case. See Table 2 for ogive case definition

where $w$ is the vertical wind velocity, $c$ is the horizontal wind velocity component or a scalar quantity (i.e. temperature and humidity), and $f$ is a frequency that corresponds to a time period $(\tau)$ as

$$
\tau=\frac{1}{f} .
$$

This analysis was applied to data obtained over the maize field (A6) of the LITFASS-2003 in Foken et al. (2006), where the ogive function was calculated from raw $20 \mathrm{~Hz}$ data over a 4-h period and mainly focused on three selected days (7-9 June 2003). It was shown that the ogive curves could be classified into three cases. Case 1 is where the ogive curve exhibits an asymptotic behavior toward the low frequency within a 30-min period. This indicates that the 30 -min averaging time is sufficient to capture most of the turbulent fluxes. Case 2 is where the ogive curve shows the extreme value (peak) within a 30 -min period, meaning that the total turbulent fluxes have been reached before $30 \mathrm{~min}$. Hence a longer averaging time obviously reduces the flux and a period shorter than $30 \mathrm{~min}$ would be sufficient to capture most of the turbulent fluxes. Case 3 is where the ogive curve does not converge within a 30 -min period. This implies that there is a significant contribution from the low frequency part of the turbulent spectrum and a 30-min averaging time is not sufficient to capture most of the fluxes.

As mentioned in Sect. 2.1, only the short-term average data at every 5 or 10 min exist for all selected sites, and we therefore developed a modified ogive analysis to deal with these data. According to the spectral analysis, the spectra calculated from high and low frequency data behave similarly in the low frequency region (Kaimal et al. 1972). This means that we can use the turbulent spectrum calculated from the short-term average data to estimate the change in turbulent fluxes after $30 \mathrm{~min}$, without any information prior to $30 \mathrm{~min}$ (Fig. 1).

We calculated the turbulent cospectra of the short-term average data with a standard fast Fourier transform (FFT) method. To avoid influences from the diurnal effect, we still keep the time extension up to $4 \mathrm{~h}$ as in Foken et al. (2006). We then determined the change in turbulent fluxes after a 30-min period from the cumulative integral of the cospectra starting 
Table 2 Ogive case definition in analogy to Foken et al. (2006)

\begin{tabular}{ll}
\hline Case & Criterion \\
\hline 1 & $\Delta_{\max } / \bar{F}_{30} \leq \eta$ \\
2 & $\Delta_{\max } / \bar{F}_{30}>\eta$ and $\Delta_{\max }<0$ \\
3 & $\Delta_{\max } / \bar{F}_{30}>\eta$ and $\Delta_{\max }>0$
\end{tabular}

$\Delta_{\max }$ is a maximum flux difference after 30 -min averaging time. $\bar{F}_{30}$ is an average size of turbulent flux at 30-min period. $\eta$ is the width of an error band. See more details in Sect. 2.3

from the frequency that corresponds to a period of $30 \mathrm{~min}$, and set its maximum value to be the maximum flux difference $\left(\Delta_{\max }\right)$, i.e.,

$$
\Delta_{\max }=\max \left(\int_{\tau=30}^{\tau} C o_{w, c}(f) \mathrm{d} f\right) .
$$

We compared $\Delta_{\max }$ with the turbulent flux at $30 \mathrm{~min}\left(\bar{F}_{30}\right)$, which we can estimate in two different ways. Firstly, by averaging the fluxes from each 30 -min block, $\left(\overline{w^{\prime} c^{\prime}}\right)_{j}$, together as

$$
\bar{F}_{30}=\frac{1}{8} \sum_{j=1}^{8}\left(\overline{w^{\prime} c^{\prime}}\right)_{j} .
$$

Secondly, we calculated the total flux over a 4-h period $\left(\bar{F}_{4 \mathrm{~h}}\right)$ from short-term average data with the help of Eq. 2 and the turbulent flux after a $30-\min$ period $\left(F_{\tau>30}\right)$ from the cumulative integral of the cospectra from the lowest frequency $\left(f_{\min }\right)$ to the frequency corresponding to a 30-min period,

$$
F_{\tau>30}=\int_{f_{\min }}^{\tau=30} C o_{\mathrm{w}, \mathrm{c}}(f) \mathrm{d} f .
$$

The difference between $\bar{F}_{4 \mathrm{~h}}$ and $F_{\tau>30}$ can give us the estimation of $\bar{F}_{30}$ as

$$
\bar{F}_{30}=\bar{F}_{4 \mathrm{~h}}-F_{\tau>30} \text {. }
$$

Both estimations in Eqs. 7 and 9 give compatible values of $\bar{F}_{30}$. We then set the error band of width $2 \eta$ for the turbulent flux at a 30-min period (Fig. 1). If $\Delta_{\max }$ is still confined within this band, it indicates that the turbulent flux difference after $30 \mathrm{~min}$ is not significant, which conforms to case 1 in Foken et al. (2006). If the maximum flux difference after a 30-min period exceeds this band, this means the turbulent flux difference is significant and could be classified into two cases, depending on the changes in turbulent fluxes after a 30-min period. It is equivalent to case 2 in Foken et al. (2006), when the size of turbulent flux decreases and case 3, when the size of turbulent flux increases. In this study, we set $\eta$ to be $10 \%$ (or $20 \%$ ) of $\bar{F}_{30}$, which must not be smaller than the measurement errors of each turbulent flux (Sect. 2.2). The ogive case definition in analogy to Foken et al. (2006) is shown in Table 2.

To extend the investigation beyond three golden days and cover more land-use types, the modified ogive analysis was applied to a selected dataset (as described in Sect. 2.2) from selected ground-based stations of the LITFASS-2003 experiment (Table 1). The modified ogive analysis was applied to all selected sites for the energy balance component, while for $F_{\mathrm{c}}$, it was only applied to these sites: maize, grass and forest. This is because $F_{\mathrm{c}}$ measurements were not available at the rye (A5) and rape (A7) sites (both equipped with $\mathrm{KH} 20$ ), and $F_{\mathrm{c}}$ 
was very low over the lake. Note that in this study, we did not apply the flux correction as mentioned in Sect. 2.1. Since each point of the cospectrum corresponds to the turbulent flux at a different duration, the choice of suitable duration for the flux corrections would be ambiguous. According to Mauder and Foken (2006), these flux corrections would reduce the residual by $17 \%$, and we may therefore assume that this reduction would have reflected in an increase of the sensible and latent heat fluxes.

\subsection{Block Ensemble Average}

The averaging operator that we apply to the single tower EC measurement is the time average. Over a period $P$, the time average of any variable $a(t)$ is (see Fig. 2 in Finnigan et al. 2003)

$$
\overline{a(t)}=\frac{1}{P} \int_{0}^{P} a(t) \mathrm{d} t .
$$

This averaging operator can apply to the mass balance equation as long as it satisfies the Reynolds averaging rules (Feriet 1951; Bernstein 1966, 1970). A standard approach is to impose a steady-state condition over a period $P$, which makes the time average constant in this period $(\overline{a(t)}=\bar{a})$. Then any variable $a(t)$ can be decomposed into mean $(\bar{a})$ and fluctuation parts $\left(a^{\prime}(t)\right)$ with the Reynolds decomposition as

$$
a(t)=\bar{a}+a^{\prime}(t) .
$$

When Eq. 11 is applied to the product of vertical velocity $w$ and variable $c$, which can be horizontal wind velocity or a scalar quantity, we obtain

$$
\overline{w(t) c(t)}=\bar{w} \bar{c}+\overline{w^{\prime} c^{\prime}},
$$

which represents the mean vertical transport of a scalar or momentum over the period $P$. This period must be long enough to capture most of the atmospheric turbulence, yet it must not violate a steady-state condition. The typical value of $P$ in most EC measurements is $30 \mathrm{~min}$. We can further simplify Eq. 12 by applying coordinate rotation, which sets $\bar{w}$ to zero, e.g., the double rotation (Kaimal and Finnigan 1994).

When the averaging period $P$ is extended to be much longer than $30 \mathrm{~min}$, it is very difficult to maintain a steady-state condition. Without a steady-state condition, the Reynolds averaging rules no longer hold, in which case the time average is no longer a good representative statistic. Finnigan et al. (2003) and Bernstein $(1966,1970)$ proposed using the block ensemble average as it always obeys the Reynolds averaging rules, allowing the formulation to be carried out without a steady-state condition.

Suppose we extend our period of interest to $N P$, which consists of $N$ consecutive blocks (or subperiods, or runs) of period $P$. Let a subscript $n$ represent the $n$th block, whose time average of any variable $a_{n}(t)$ in this block is $\bar{a}_{n}(t)$. This time average becomes a function of time because it can vary from block to block. The block ensemble average of all $N$ blocks (denoted by \langle\rangle ) of $a_{n}(t)$ over period $N P$ is

$$
\langle\bar{a}\rangle=\frac{1}{N} \sum_{n=1}^{N} \bar{a}_{n}(t),
$$

where $\langle\bar{a}\rangle$ is always constant over the period NP and obeys Reynolds averaging rules. This allows us to use the block ensemble average operator with the mass balance equation. The time average of each block $\bar{a}_{n}(t)$ deviates from $\langle\bar{a}\rangle$ by $\tilde{a}_{n}(t)$,

$$
\tilde{a}_{n}(t)=\bar{a}_{n}(t)-\langle\bar{a}\rangle \text {. }
$$


Hence we replace the Reynolds decomposition by the triple decomposition, in which any variable in the $n$th block can be separated into three parts as (see Fig. 3 in Finnigan et al. 2003)

$$
a_{n}(t)=\langle\bar{a}\rangle+\tilde{a}_{n}(t)+a^{\prime}(t),
$$

where $\tilde{a}_{n}(t)$ is the block-to-block fluctuation with contributions from eddies with time scales from $P$ to $N P$, while $a^{\prime}(t)$ is an instantaneous fluctuation. This triple decomposition leads to the block ensemble average of the vertical transport of momentum or scalar over $N$ blocks of period $P$ as (we drop the subscript $n$ and omit $t$ )

$$
\langle\overline{w(t) c(t)}\rangle=\langle\overline{w c}\rangle=\langle\bar{w}\rangle\langle\bar{c}\rangle+\langle\tilde{w} \tilde{c}\rangle+\left\langle\overline{w^{\prime} c^{\prime}}\right\rangle .
$$

This shows that the mean vertical flux average over a period $N P$ does not only depend on the usual turbulent flux $\overline{w^{\prime} c^{\prime}}$, but also depends on the flux caused by block to block variations $\tilde{w} \tilde{c}$ (also known as 'mesoscale flux' in the literature, e.g. Nakamura and Mahrt 2006). In Bernstein (1966), the moving average or overlapped block ensemble average was used instead of a non-overlapped one as in Finnigan et al. (2003).

To use the block ensemble average, every single block in period $N P$ must be in the same coordinate system: the long-term coordinate. It has been shown in Finnigan et al. (2003) that a period-to-period rotation, e.g. the double rotation, is not a long-term coordinate. It sets $\bar{w}$ of each $n$th period to zero and acts as a high-pass filter. In our analysis, we obtained the longterm coordinate through the planar fit rotation (Paw et al. 2000; Wilczak et al. 2001), which determines the rotation angle from multiple periods. This rotation set the block ensemble average of vertical velocity of the period $N P$ to zero $(\langle\bar{w}\rangle=0)$, while the mean vertical velocity in each period $P$ is not necessarily zero. Thus the block ensemble average of the vertical flux becomes

$$
\langle\overline{w c}\rangle=\langle\tilde{w} \tilde{c}\rangle+\left\langle\overline{w^{\prime} c^{\prime}}\right\rangle
$$

where, according to Finnigan et al. (2003), $\tilde{w} \tilde{c}$ has two roles, viz.

1. To balance the unsteady horizontal flux divergence and transient changes in source and storage terms.

2. To carry the low frequency contribution to the long-term vertical flux.

The first role can cause $\tilde{w} \tilde{c}$ to become very large in any arbitrary period, which can be much larger than the mean vertical flux itself. It was suggested that the period $N P$ must be long enough to suppress and minimize the effect of the first role. Then only the second role would contribute to the vertical flux. In our case, in addition to suppressing the transient effect, we would like to suppress the diurnal effect as well, so an observation period over a few days would help to balance the strong daytime fluxes with the weak nighttime fluxes as well as suppress any extreme days in between. Therefore, only the low frequency part of the diurnal effects would remain. However, an observation period over a few days would also intensify any errors in $\tilde{w} \tilde{c}$, typically from instrumentation drift, gaps and synoptic-scale events. Since our observation period lasted only about a month and all sensors were carefully checked, instrumentation drift can be neglected. Hence, we need to select an observation period not influenced by any synoptic events, and with minimum gaps, to minimize the errors.

This approach was applied with the dataset from the Amazonian rain forest in Finnigan et al. (2003), where it was shown that the residual goes to zero at around $4 \mathrm{~h}$. A similar strategy was applied to the 15-day dataset from the maize field (A6) of the LITFASS-2003 experiment during the period 2 June 2003, 1800 UTC-18 June 2003, 0000 UTC (Mauder and Foken 2006), which we also used in our study as a period $N P$. Overlapping blocks ensemble 
averages were used, with the starting point of each consecutive block being shifted by 5 min, where the period $P$ of the block ensemble average was varied from 5 min to 5 days. Flux corrections were applied as described in Sect. 2.1 in each individual block. It was shown that the energy balance was closed within a day and mainly due to the increase of $\left\langle Q_{\mathrm{H}}\right\rangle$.

In the present study, to investigate whether this approach could generally close the energy balance, we applied the block ensemble average to selected ground-based stations of the LITFASS-2003 experiment as listed in Table 1 and used an identical period as in Mauder and Foken (2006). We made slight changes compared to Mauder and Foken (2006), because the turbulent data from lake and forest as well as the ground heat fluxes and net radiations from most selected stations are only available every $10 \mathrm{~min}$. Our block ensemble period $P$ was varied from 10 min to 5 days, with the starting points of each consecutive block being shifted by $10 \mathrm{~min}$. We also used the same flux corrections as in Mauder and Foken (2006).

\subsection{Scale Analysis}

Since we are interested in how secondary circulations contribute to the low frequency part of the turbulent spectra, we used the wavelet analysis to resolve the underlying scale of motion. The wavelet analysis routine employed in this study is similar to Mauder et al. (2007), which is based on the algorithm described in Torrence and Compo (1998). The Morlet wavelet was used in this routine due to its localization strength in the frequency domain. We can only apply the wavelet analysis to the data from rye, maize and grassland, whose high frequency data are available. The $\mathrm{CO}_{2}$ flux is not discussed, as it is not related to the energy balance. Other than the high frequency data requirement, the wavelet analysis also consumes large amounts of computing resources, so it is almost impossible to apply over quite large datasets. Therefore, a specific period when large-scale structures exist needs to be identified before the wavelet analysis is performed over this specific period.

\section{Results and Discussion}

\subsection{Modified Ogive Analysis}

As mentioned in Sect. 2.3, we investigated the impact of averaging time extension with the modified ogive analysis on energy balance components and $F_{\mathrm{c}}$ separately. Our data selection criteria (Sect. 2.2) ruled out most nighttime periods in both analyses, because their turbulent fluxes were below thresholds. We expected measuring stations with broader undisturbed wind sectors, namely rye (A5), grass (NV) and forest (HV), to have more qualified periods. This was confirmed by the highest number of qualified periods from grass and rye stations, however, the number of qualified periods of the forest station for the modified ogive analysis of the energy balance components was less than for the other two measuring stations. This is because measurements of $Q_{\mathrm{E}}$ at the forest were often rejected due to poor steady-state conditions during daytime. This contrasts with data from the lake (FS), where $Q_{\mathrm{H}}$ was often rejected for the same reason. Over low vegetation, steady-state flags of $Q_{\mathrm{H}}$ and $Q_{\mathrm{E}}$ were normally qualified during 0600-1600 UTC. Some random unsteady periods mostly appeared in the afternoon. For all selected measuring stations, steady-state flags of $F_{\mathrm{c}}$ (if measurements were available) were randomly disqualified throughout the day, while steady-state flags of $u_{*}$ were mostly qualified. Hence, passing the steady-state criterion is mainly dependent on the stationarity of $Q_{\mathrm{H}}, Q_{\mathrm{E}}$ and $F_{\mathrm{c}}$. In the end, at each measuring station, only 5-20\% of available periods were left for the modified ogive analysis, and these periods occurred mainly during 
Table 3 Results from the modified ogive analysis of the energy balance components $\left(Q_{\mathrm{H}}\right.$ and $\left.Q_{\mathrm{E}}\right)$ from selected stations of the LITFASS-2003 experiment between 20 May 2003, 1200 UTC-18 June 2003, 0000 UTC

\begin{tabular}{|c|c|c|c|c|c|c|c|c|c|c|}
\hline \multirow{2}{*}{$\begin{array}{l}\text { Station } \\
\text { (Tot no.) }\end{array}$} & \multirow[t]{2}{*}{ Flux } & \multirow{2}{*}{$\begin{array}{l}\eta \\
(\%)\end{array}$} & \multicolumn{2}{|l|}{ Case 1} & \multicolumn{3}{|l|}{ Case 2} & \multicolumn{3}{|l|}{ Case 3} \\
\hline & & & $\left\langle\bar{F}_{30}\right\rangle$ & no. $(\%)$ & $\left\langle\bar{F}_{30}\right\rangle$ & $\left\langle\Delta_{\max }\right\rangle$ & no. $(\%)$ & $\left\langle\bar{F}_{30}\right\rangle$ & $\left\langle\Delta_{\max }\right\rangle$ & no. $(\%)$ \\
\hline \multirow{4}{*}{$\begin{array}{l}\text { Forest } \\
\text { HV } \\
(123)\end{array}$} & \multirow[t]{2}{*}{$Q_{\mathrm{H}}$} & 10 & 261 & 74.8 & 205 & -33 & 3.3 & 224 & 33 & 22.0 \\
\hline & & 20 & 252 & 96.7 & 237 & -56 & 0.8 & 217 & 70 & 2.4 \\
\hline & \multirow[t]{2}{*}{$Q_{\mathrm{E}}$} & 10 & 107 & 43.1 & 128 & -33 & 9.8 & 119 & 27 & 47.2 \\
\hline & & 20 & 112 & 75.6 & 126 & -45 & 4.9 & 125 & 40 & 19.5 \\
\hline \multirow{4}{*}{$\begin{array}{l}\text { Rye } \\
\text { A5 } \\
(218)\end{array}$} & \multirow[t]{2}{*}{$Q_{\mathrm{H}}$} & 10 & 148 & 88.1 & 99 & -15 & 2.8 & 85 & 19 & 9.2 \\
\hline & & 20 & 143 & 97.7 & - & - & 0.0 & 61 & 36 & 2.3 \\
\hline & \multirow[t]{2}{*}{$Q_{\mathrm{E}}$} & 10 & 145 & 89.9 & 118 & -20 & 4.6 & 131 & 23 & 5.5 \\
\hline & & 20 & 143 & 97.2 & 116 & -26 & 0.9 & 132 & 30 & 1.8 \\
\hline \multirow{4}{*}{$\begin{array}{l}\text { Maize } \\
\text { A6 } \\
(117)\end{array}$} & \multirow{2}{*}{$Q_{\mathrm{H}}$} & 10 & 106 & 84.6 & 98 & -12 & 2.6 & 116 & 28 & 12.8 \\
\hline & & 20 & 108 & 94.9 & - & - & 0.0 & 92 & 39 & 5.1 \\
\hline & \multirow[t]{2}{*}{$Q_{\mathrm{E}}$} & 10 & 134 & 82.9 & 77 & -20 & 12.0 & 80 & 18 & 5.1 \\
\hline & & 20 & 127 & 95.7 & 91 & -37 & 2.6 & 57 & 22 & 1.7 \\
\hline Rape & \multirow[t]{2}{*}{$Q_{\mathrm{H}}$} & 10 & 127 & 90.4 & 83 & -13 & 8.5 & 94 & 12 & 1.1 \\
\hline A7 & & 20 & 123 & 100.0 & - & - & 0.0 & - & - & 0.0 \\
\hline \multirow[t]{2}{*}{ (94) } & \multirow[t]{2}{*}{$Q_{\mathrm{E}}$} & 10 & 181 & 98.9 & - & - & 0.0 & 141 & 16 & 1.1 \\
\hline & & 20 & 181 & 100.0 & - & - & 0.0 & - & - & 0.0 \\
\hline Grass & \multirow[t]{2}{*}{$Q_{\mathrm{H}}$} & 10 & 117 & 93.0 & 101 & -15 & 6.0 & 132 & 23 & 1.0 \\
\hline NV & & 20 & 116 & 99.5 & 99 & -27 & 0.5 & - & - & 0.0 \\
\hline \multirow[t]{2}{*}{ (201) } & \multirow[t]{2}{*}{$Q_{\mathrm{E}}$} & 10 & 131 & 86.1 & 95 & -19 & 2.0 & 118 & 19 & 11.9 \\
\hline & & 20 & 140 & 97.5 & 94 & -31 & 0.5 & 114 & 27 & 2.0 \\
\hline Lake & \multirow[t]{2}{*}{$Q_{\mathrm{H}}$} & 10 & 40 & 95.8 & - & - & 0.0 & 31 & 14 & 4.2 \\
\hline FS & & 20 & 40 & 100.0 & - & - & 0.0 & - & - & 0.0 \\
\hline \multirow[t]{2}{*}{ (72) } & \multirow[t]{2}{*}{$Q_{\mathrm{E}}$} & 10 & 197 & 95.8 & 93 & -15 & 1.4 & 121 & 14 & 2.8 \\
\hline & & 20 & 193 & 100.0 & - & - & 0.0 & - & - & 0.0 \\
\hline
\end{tabular}

Each station is identified by the canopy type and station code (column 1)

Tot no. the number of qualified periods for the modified ogive analysis, $\eta$ the width of the error band, which is set to be 10 and $20 \%$ of $\bar{F}_{30}$ (average flux at 30-min period of each run) and has a minimum value equal to the measurement error of each turbulent flux, $\left\langle\bar{F}_{30}\right\rangle$ the average of $\bar{F}_{30}$ from all runs in each ogive case, no. is the percentage of qualified periods in each ogive case, $\left\langle\Delta_{\max }\right\rangle$ the average of $\Delta_{\max }$ (maximum flux difference) from in each ogive case

Note that the unit of each specified flux in column 2 only applies to quantities in columns 4, 6, 7, 9 and 10 of the same row

0600-1600 UTC. For the energy balance components, all periods had unstable stratification, while for $F_{\mathrm{c}}$, there were a few periods with stable stratification.

The results of the modified ogive analysis of energy balance components and $F_{\mathrm{c}}$ are shown in Tables 3 and 4, respectively. The different analyses both gave very similar results for $u_{*}$. Hence, only the results of $u_{*}$ from the modified ogive analysis of $F_{\mathrm{c}}$ (Table 4 ) are shown. In these two Tables, each measuring station is identified by the canopy type and the station code (column 1). We report the number of qualified periods for the modified ogive analysis (Tot no., column 1), the average of $\bar{F}_{30}\left(\left\langle\bar{F}_{30}\right\rangle\right.$, column 4, 6 and 9), and the percentage of qualified periods in each ogive case (no., column 5, 8 and 11). All sets of information are reported at two different sizes of error bands $(\eta), 10$ and $20 \%$, which must be larger than 
Table 4 Results from the modified ogive analysis of friction velocity $\left(u_{*}\right)$ and $\mathrm{CO}_{2}$ flux $\left(F_{\mathrm{c}}\right)$

\begin{tabular}{|c|c|c|c|c|c|c|c|c|c|c|}
\hline \multirow{2}{*}{$\begin{array}{l}\text { Station } \\
\text { (Tot no.) }\end{array}$} & \multirow[t]{2}{*}{ Flux } & \multirow{2}{*}{$\begin{array}{l}\eta \\
(\%)\end{array}$} & \multicolumn{2}{|l|}{ Case 1} & \multicolumn{3}{|l|}{ Case 2} & \multicolumn{3}{|l|}{ Case 3} \\
\hline & & & $\left\langle\bar{F}_{30}\right\rangle$ & no. $(\%)$ & $\left\langle\bar{F}_{30}\right\rangle$ & $\left\langle\Delta_{\max }\right\rangle$ & no. $(\%)$ & $\left\langle\bar{F}_{30}\right\rangle$ & $\left\langle\Delta_{\max }\right\rangle$ & no. $(\%)$ \\
\hline Forest & $u_{*}$ & 10 & 0.64 & 99.5 & - & - & 0.0 & 0.38 & 0.06 & 0.5 \\
\hline $\mathrm{HV}$ & $\left(\mathrm{m} \mathrm{s}^{-1}\right)$ & 20 & 0.64 & 100.0 & - & -2.48 & 0.0 & - & - & 0.0 \\
\hline \multirow[t]{2}{*}{ (192) } & $F_{\mathrm{c}}$ & 10 & 8.68 & 58.3 & 8.25 & -1.57 & 12.5 & 7.43 & 1.54 & 29.2 \\
\hline & $\left(\mu \mathrm{molm} \mathrm{m}^{-2} \mathrm{~s}^{-1}\right)$ & 20 & 8.29 & 89.1 & 7.73 & -2.48 & 4.2 & 8.21 & 3.23 & 6.8 \\
\hline Maize & $u_{*}$ & 10 & 0.31 & 97.4 & 0.26 & -0.03 & 0.9 & 0.15 & 0.03 & 1.8 \\
\hline A6 & $\left(\mathrm{m} \mathrm{s}^{-1}\right)$ & 20 & 0.31 & 100.0 & - & -1.70 & 0.0 & - & - & 0.0 \\
\hline \multirow[t]{2}{*}{ (114) } & $F_{\mathrm{c}}$ & 10 & 9.09 & 62.3 & 7.13 & -1.56 & 14.0 & 7.34 & 2.40 & 23.7 \\
\hline & $\left(\mu \mathrm{molm} \mathrm{m}^{-2} \mathrm{~s}^{-1}\right)$ & 20 & 8.69 & 78.9 & 7.10 & -1.70 & 10.5 & 7.52 & 4.09 & 10.5 \\
\hline Grass & $u_{*}$ & 10 & 0.33 & 88.8 & - & - & 0.0 & 0.27 & 0.04 & 11.2 \\
\hline NV & $\left(\mathrm{m} \mathrm{s}^{-1}\right)$ & 20 & 0.33 & 96.6 & - & - & 0.0 & 0.22 & 0.05 & 3.4 \\
\hline \multirow[t]{2}{*}{ (206) } & $F_{\mathrm{c}}$ & 10 & 9.95 & 74.3 & 8.80 & -1.67 & 14.1 & 7.65 & 1.27 & 11.7 \\
\hline & $\left(\mu \mathrm{molm} \mathrm{m}^{-2} \mathrm{~s}^{-1}\right)$ & 20 & 9.57 & 94.7 & 8.47 & -2.74 & 3.9 & 9.41 & 2.82 & 1.5 \\
\hline
\end{tabular}

The description is similar to Table 3

the threshold fluxes (Sect. 2.2). For cases 2 and 3, the average of maximum flux difference $\left(\left\langle\Delta_{\max }\right\rangle\right.$, columns 7 and 10) is also presented.

$\left\langle\bar{F}_{30}\right\rangle$ of $Q_{\mathrm{H}}$ and $Q_{\mathrm{E}}$ were closely grouped over low vegetation. $\left\langle\bar{F}_{30}\right\rangle$ of $Q_{\mathrm{H}}$ was largest over the forest and smallest over the lake, and vice versa for $Q_{\mathrm{E}}$. Over lake and low vegetation, the modified ogive analysis classified most qualified periods of both $Q_{\mathrm{H}}$ and $Q_{\mathrm{E}}$ as case 1 . This suggests that a 30-min averaging time is generally sufficient to capture most turbulent fluxes. However, there were significant numbers of cases 2 and 3 of both $Q_{\mathrm{H}}$ and $Q_{\mathrm{E}}$ from rye, grass, maize and, remarkably, forest stations. These periods of cases 2 and 3 of rye, grass and maize sites were closely related to the stationarity of $Q_{\mathrm{H}}$ and $Q_{\mathrm{E}}$ over a 4-h period. For these three sites, periods of case 1 usually had a 4-h steady-state flag of 1 for $Q_{\mathrm{H}}$ and $Q_{\mathrm{E}}$, while cases 2 and 3 usually had steady-state flags of 2 or greater. This relation was not readily apparent in the forest site, implying that when the atmosphere becomes less stationary at longer averaging time, the measured fluxes over low vegetation can be either increased or decreased. If we restrict our consideration to rye, grass, maize and forest sites, we found that the number of case 3 was normally greater than the number of case 2 in both $Q_{\mathrm{H}}$ and $Q_{\mathrm{E}}$. This would tell us that the averaging time extension most likely increases $Q_{\mathrm{H}}$ and $Q_{\mathrm{E}}$. The average maximum flux difference $\left(\left\langle\Delta_{\max }\right\rangle\right)$ for $Q_{\mathrm{H}}$ was mostly higher than for $Q_{\mathrm{E}} \cdot\left\langle\Delta_{\max }\right\rangle$ is increased with larger size of an error band $(\eta)$, while lower numbers of cases 2 and 3 were observed. This would indicate that the fewer periods left had a larger $\left\langle\Delta_{\max }\right\rangle$. However, even with the greatest $\left\langle\Delta_{\max }\right\rangle$ added on top of flux corrections, the energy increase is still not sufficient to close the energy balance. Furthermore, from scalar similarity of $Q_{\mathrm{H}}$ and $Q_{\mathrm{E}}$, we expected these fluxes to increase or decrease together. This means we should see case 2 or case 3 in both $Q_{\mathrm{H}}$ and $Q_{\mathrm{E}}$ simultaneously, which was rarely observed.

Values of $\left\langle\bar{F}_{30}\right\rangle$ of $u_{*}$ were highest over the forest and smallest over the lake, and were closely grouped together over low vegetation. Our modified ogive analysis classified most periods from all sites as case 1 . This suggests that the time extension has almost no impact on $u_{*}$, regardless of canopy types.

For $F_{\mathrm{c}}$, all sites gave comparable values of $\left\langle\bar{F}_{30}\right\rangle$. Case 1 was still in the majority, with a larger fraction of cases 2 and 3 than the energy balance components. Forest also had larger 

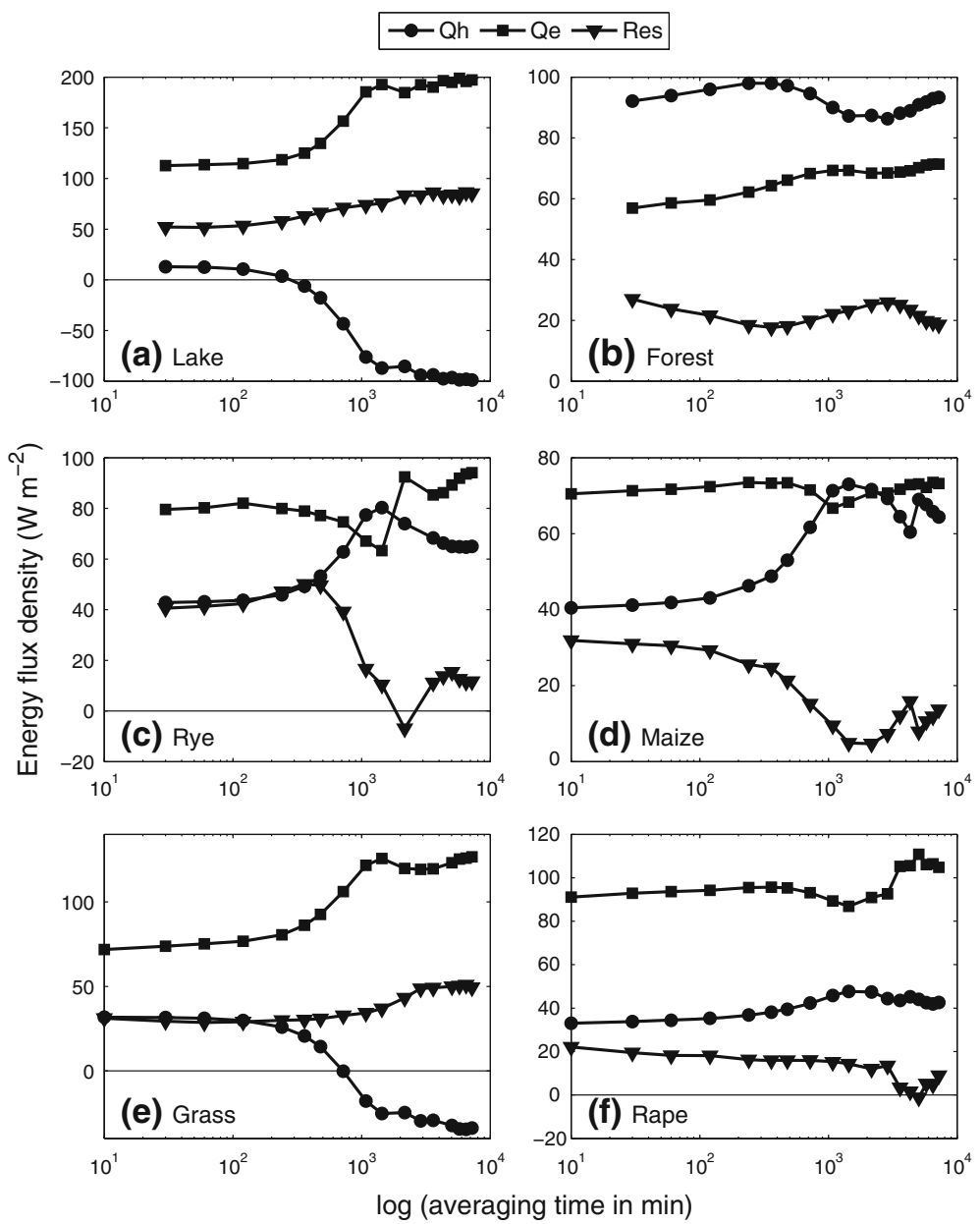

Fig. 2 Block ensemble averages of sensible heat flux and latent heat flux (Eq. 17 with $c$ as temperature and absolute humidity), and their corresponding residuals, during 2 June 2003, 1800 UTC-18 June 2003, 0000 UTC of selected sites in the LITFASS-2003 experiment: a lake, b forest, $\mathbf{c}$ rye, $\mathbf{d}$ maize (from Mauder and Foken (2006)), e grass and f barley

fraction of cases 2 and 3 than did low vegetation. Overall, there was a greater number of case 3 than number of case 2 , and $\left\langle\Delta_{\max }\right\rangle$ also increased with $\eta$. The 4-h steady-state flags were normally 1 for case 1 and higher for cases 2 and 3. However, case 2 generally had higher steady-state flags than case 3 . This suggests that when the atmosphere becomes less stationary at longer averaging times, the measured values of $F_{\mathrm{c}}$ tend to increase. However, when the degree of unsteadiness becomes stronger, the measured values of $F_{\mathrm{c}}$ start to decrease.

\subsection{Block Ensemble Average}

The block ensemble averages (Eq. 17) for all selected sites during 2 June 2003, 1800 UTC-18 June 2003, 0000 UTC, are shown in Fig. 2. We chose this period as our observation period $N P$ to repeat Mauder and Foken (2006), with some minor modifications (Sect. 2.4). We 
found that our result from the maize station (Fig. 2d) differed from the original by less than the measurement errors of $Q_{\mathrm{H}}$ and $Q_{\mathrm{E}}$. Therefore, these modifications still give the same results and we can confidently apply them to the data from other selected measuring stations.

The outcome of the block ensemble averaging was quite unexpected to us. It could close the energy balance over only maize, rye and rape sites. For maize and rye sites, the closures were at around 15-30 h, which is close to the results obtained in Mauder and Foken (2006). These closures were mainly caused by an increase of $\left\langle Q_{\mathrm{H}}\right\rangle$ with a longer block ensemble averaging period $P$. For the rape site, both $\left\langle Q_{\mathrm{H}}\right\rangle$ and $\left\langle Q_{\mathrm{E}}\right\rangle$ were approximately constant at all values of $P$. During the observation period, this site was also influenced by rain events in the southern part of the LITFASS area. Therefore, its closure at very large values of $P$ was not enhanced by the block ensemble average. For grassland and lake, $\left\langle Q_{\mathrm{H}}\right\rangle$ was decreased with greater $P$, which was canceled by the increase in $\left\langle Q_{\mathrm{E}}\right\rangle$, and caused the residual to be approximately constant at all values of $P$. For lake and forest sites, we must interpret the results carefully, because the lake has different characteristics from other terrain sites and we cannot precisely estimate the canopy heat storage (Sect. 2.1) of the forest from our data.

At all sites, both $\left\langle Q_{\mathrm{H}}\right\rangle$ and $\left\langle Q_{\mathrm{E}}\right\rangle$ were approximately constant within the first few hours. Over longer $P,\left\langle Q_{\mathrm{E}}\right\rangle$ was more steady than $\left\langle Q_{\mathrm{H}}\right\rangle$. The inflection at the diurnal scale was found at all sites of both $\left\langle Q_{\mathrm{H}}\right\rangle$ and $\left\langle Q_{\mathrm{E}}\right\rangle$. As all these selected sites are practically in the same $20 \times 20 \mathrm{~km}^{2}$ area, the diurnal effects should not be very different and the degree of inflection should be comparable. Therefore, the stronger inflection over some sites and fluxes may not be entirely caused by the diurnal effects.

As the block ensemble average could not close the energy balance for all selected sites from 2 June 2003, 1800 UTC to 18 June 2003, 0000 UTC, we need to determine the reason for this and whether it would be the same in a different observation period $N P$. We know that the $\tilde{w} \tilde{c}$ term of the block ensemble average is related to the low frequency flux contribution. In principle, $\tilde{w} \tilde{c}$ represents the flux contributions beyond the averaging period $P$. If we set $P$ to be $30 \mathrm{~min}, \tilde{w} \tilde{c}$ would represent additional flux after the 30 -min averaging time. Hence, long-term observation of $\tilde{w} \tilde{c}$ would show variation of additional fluxes from low frequency contributions, which may be related to observed block ensemble average fluxes. These variations can be observed more clearly when the observation period $N P$ is sufficiently long to suppress any transient effects in the block ensemble average fluxes.

Our observation period $N P$, which covered an entire period of the LITFASS-2003 experiment, was 20 May 2003, 1200 UTC-18 June 2003, 0000 UTC. We used $\tilde{w} \tilde{c}$ from all 30-min non-overlapping blocks $(P=30 \mathrm{~min})$ within this period $N P$ to construct the Hovmøller diagrams of $\tilde{Q}_{\mathrm{H}}$ (mesoscale flux of sensible heat or $\tilde{w} \tilde{T}$ in units of energy, $T$ is temperature) and $\tilde{Q}_{\mathrm{E}}$ (mesoscale flux of latent heat or $\tilde{w} \tilde{a}$ in units of energy, $a$ is absolute humidity). These diagrams show the variation of additional fluxes beyond the 30-min averaging interval. According to Sect. 2.4, $\tilde{w} \tilde{c}$ can be very large in any arbitrary blocks. We therefore expected to observe some randomly occurring large $\tilde{Q}_{\mathrm{H}}$ and $\tilde{Q}_{\mathrm{E}}$ in these diagrams.

The Hovmøller diagrams of $\tilde{Q}_{\mathrm{H}}$ for rye and grassland are shown in Fig. 3. Throughout the entire experiment, we found large $\tilde{Q}_{\mathrm{H}}$ more often than large $\tilde{Q}_{\mathrm{E}}$. We started with the period during 2 June 2003, 1800 UTC-18 June 2003, 0000 UTC. Within this period, large $\tilde{Q}_{\mathrm{H}}$ were mainly positive for the rye (Fig. 3a) and maize (not shown) sites, and mainly negative over the grassland (Fig. 3b). These observations are consistent with the observed block ensemble average fluxes, in which $\left\langle Q_{\mathrm{H}}\right\rangle$ increased with increasing $P$ for the rye and maize sites, and vice versa for the grassland (Fig. 2). The lake site is more dominated by large negative $\tilde{Q}_{\mathrm{H}}$ (not shown), which is consistent with the decrease of $\left\langle Q_{\mathrm{H}}\right\rangle$ at longer $P$. There were only few large $\tilde{Q}_{\mathrm{E}}$ at all sites, which are consistent with approximately constant $\left\langle Q_{\mathrm{E}}\right\rangle$ at all values of 
Fig. 3 The Hovmøller diagrams of $\tilde{Q}_{\mathrm{H}}$ (mesoscale flux of sensible heat) from a rye, $\mathbf{b}$ grass and c $90-\mathrm{m}$ tower, representing $\tilde{w} \tilde{T}$ of each 30 -min block in units of energy. Series of large $\tilde{Q}_{\mathrm{H}}$ were observed in rye (positive) and grass (mainly negative) during 1 June 2003-5 June 2003. These patterns are related to secondary circulations, which is consistent with frequent observations of large $\tilde{Q}_{\mathrm{H}}$ at $90-\mathrm{m}$ height. Each colour depicts the flux in $\mathrm{W} \mathrm{m}{ }^{-2}$.

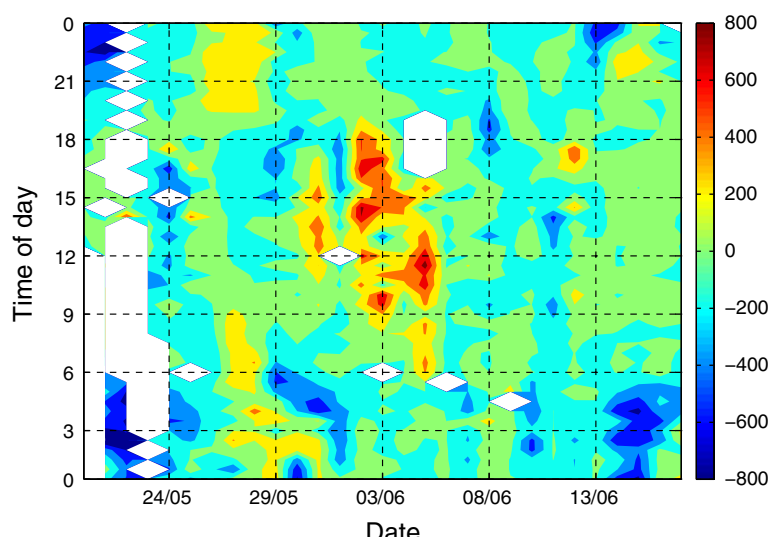

(a) Rye

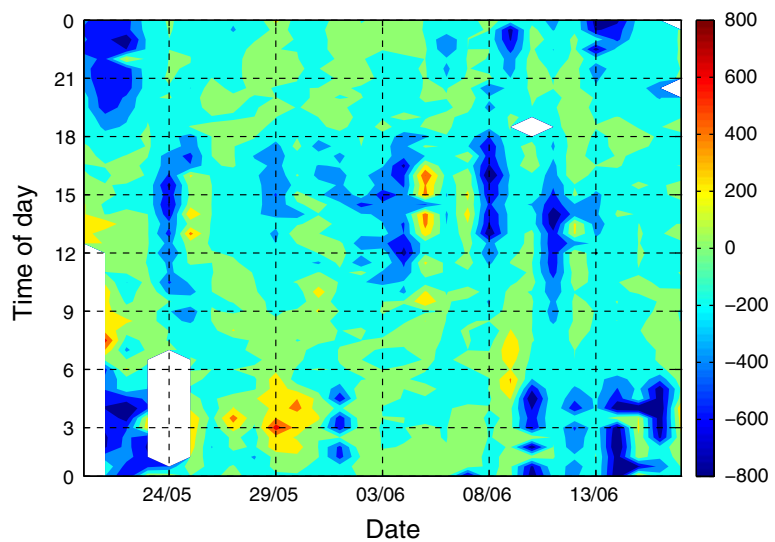

(b) Grass

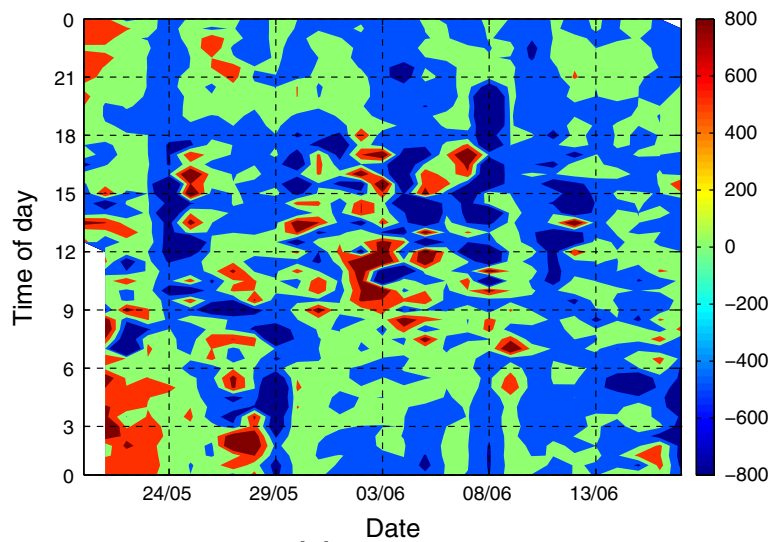

(c) 90-m tower 
$P$ over rye, maize, rape and forest sites. However, over lake and grassland, these few large $\tilde{Q}_{\text {E }}$ were extremely large when compared to their own block ensemble averages, and caused $\left\langle Q_{\mathrm{E}}\right\rangle$ to increase with increasing $P$.

More interestingly, large $\tilde{Q}_{\mathrm{H}}$ were observed consecutively for a few days during 1 June 2003-5 June 2003, over rye, maize, grass and lake. This period was the dry period between the rain events and was not influenced by any significant synoptic events. These large $\tilde{Q}_{\mathrm{H}}$ were positive for rye and maize, and mainly negative for grass and lake. Large $\tilde{Q}_{\mathrm{E}}$ was not found in this same period. As described in Sect. 2.4, large $\tilde{Q}_{\mathrm{H}}$ (or large $\tilde{w} \tilde{T}$ ) could compensate for a strong horizontal divergence in an individual block. However, consecutive occurrences indicate that they were certainly not transient effects. A strong horizontal divergence would imply a strong horizontal advection, which is related to secondary circulations. Hence, we believe that these patterns of large $\tilde{Q}_{\mathrm{H}}$ were caused by near-surface secondary circulations. To support this statement, we inspected the Hovmøller diagram of $\tilde{Q}_{\mathrm{H}}$ obtained from the measurement at $90 \mathrm{~m}$ height (M90). At this height, there always exist secondary circulations, which means that we should observe series of large $\tilde{Q}_{\mathrm{H}}$ more often than in ground measurements. We did actually observe series of large positive and negative $\tilde{Q}_{\mathrm{H}}$ throughout the entire period of the LITFASS-2003 experiment (Fig. 3c).

To observe the effect of near-surface secondary circulations more clearly, we chose 1 June 2003, 1500 UTC-5 June 2003, 1500 UTC as the new observation period N P. We used the beginning and ending time of 1500 UTC to avoid gaps in the data from the maize field on the morning of 1 June 2003 and the rain event on the evening of 5 June 2003. In addition, we wanted to complete a daily cycle. Since this period only lasted for 4 days, the block ensemble averaging period $P$ was varied from $10 \mathrm{~min}$ to 3 days. The block ensemble averages of this new observation period are shown in Fig. 4. As expected, we found that during this period, the energy balance is closed when averaging times of half a day are used for rye and maize sites. Over grassland and lake, $\left\langle Q_{\mathrm{H}}\right\rangle$ decreased at larger $P$, which corresponds to the large negative $\tilde{Q}_{\mathrm{H}} \cdot\left\langle Q_{\mathrm{E}}\right\rangle$ were approximately constant at all $P$ at all sites, which is consistent with the absence of large $\tilde{Q}_{\mathrm{E}}$.

Accepted models state that secondary circulations can only reach down to levels near the earth's surface under the free convection condition, which occurs when the buoyancy term dominates the shear production term, as $z / L \leq-1$. This situation is also accompanied by low friction velocity (Eigenmann et al. 2009). As we did not observe any free convection during 1 June 2003, 1500 UTC-5 June 2003, 1500 UTC, we believe that these near-surface secondary circulations were caused (either thermally or mechanically) by the surface heterogeneity between different land-use types (Stoy et al. 2013).

\subsection{Scale Analysis}

We used the wavelet analysis to resolve the scales of motion during 1 June 2003, 1500 UTC-5 June, 20031500 UTC with data from the rye, maize and grassland stations. The wavelet analyses of rye and grassland stations are shown in Figs. 5 and 6, respectively. Results for the maize field and the rye field are very similar. From these wavelet crossscalograms, we found small and large scales of motion. The duration of the small scales is around a few min, which should be captured by the eddy-covariance measurement over a 30-min averaging period. They are present during the daytime at all sites and transport both $Q_{\mathrm{H}}$ and $Q_{\mathrm{E}}$. The size of the larger scale is approximately one day, and mainly transports $Q_{\mathrm{H}}$. It tends to increase $Q_{\mathrm{H}}$ in the maize and rye sites, while decreasing $Q_{\mathrm{H}}$ over grass. This is consistent with the patterns of $\tilde{Q}_{\mathrm{H}}$ and the block-ensemble average fluxes. This scale 

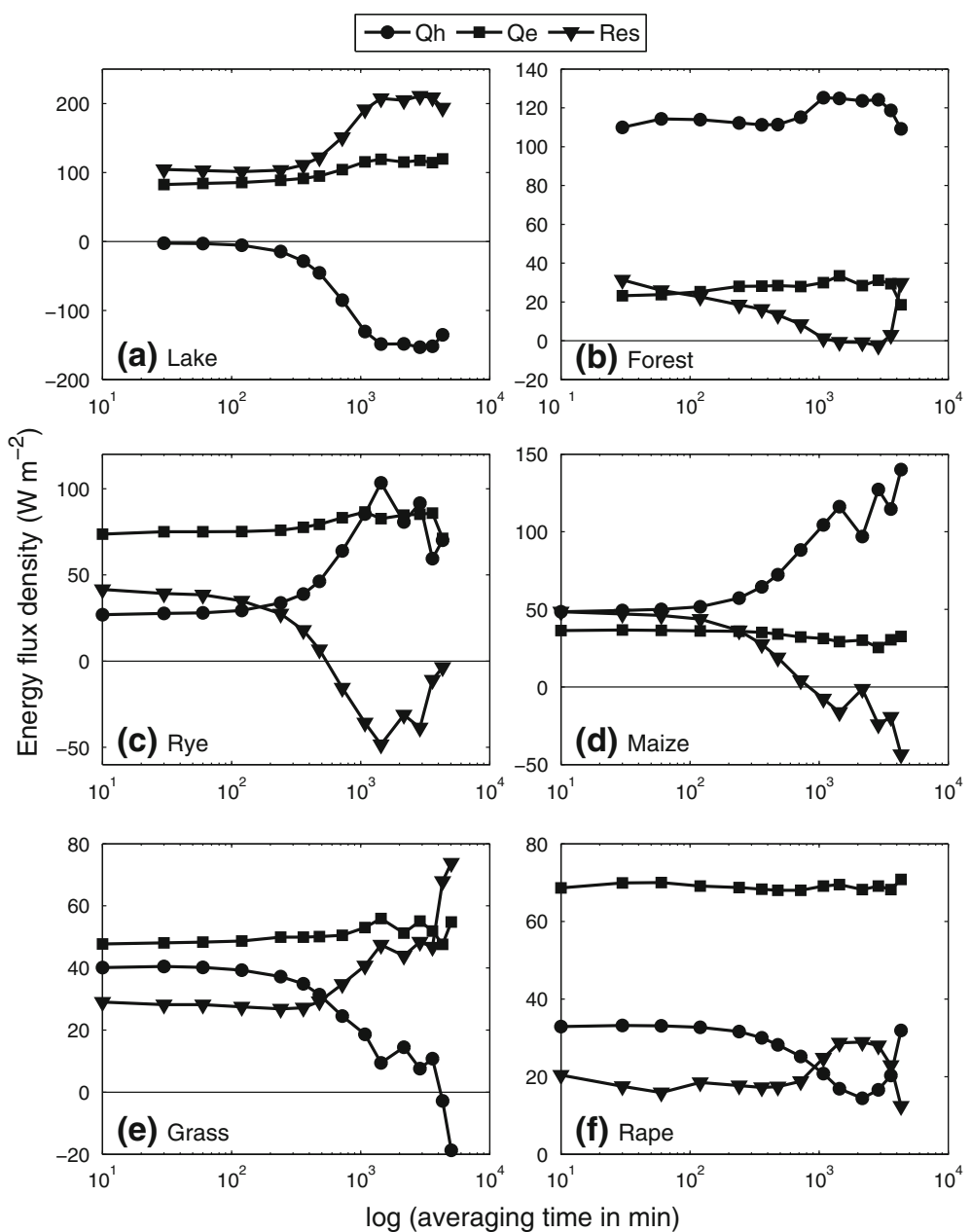

Fig. 4 Block ensemble averages of sensible heat flux and latent heat flux (Eq. 17 with $c$ as temperature and absolute humidity), and their corresponding residuals, during 1 June 2003, 1500 UTC-5 June 2003, 1500 UTC for selected sites in the LITFASS-2003 experiment: a lake, $\mathbf{b}$ forest, $\mathbf{c}$ rye, $\mathbf{d}$ maize, e grass and $\mathbf{f}$ barley

of motion would not be captured by the eddy-covariance measurement over the 30-min averaging period.

Both patterns from the Hovmøller diagram and the wavelet cross-scalograms show the increase or decrease of $\tilde{Q}_{\mathrm{H}}$. However, they do not actually show what contributes to these changes. For the turbulent fluxes $\left(\overline{w^{\prime} c^{\prime}}\right)$, which are caused by instantaneous fluctuations, we can carry out a quadrant analysis by dividing instantaneous contributions of $\overline{w^{\prime} c^{\prime}}$ into four quadrants of $w^{\prime}$ and $c^{\prime}$ (Shaw 1985). Our findings suggest that the main contribution to closing the energy balance is made by $\tilde{Q}_{\mathrm{H}}$, which results from block-to-block fluctuations $(\tilde{w}$ and $\tilde{c})$. We therefore divided block-to-block contributions of $\tilde{w} \tilde{c}$ into four quadrants of $\tilde{w}$ and $\tilde{c}$. We used $\tilde{T}$ (temperature) and $\tilde{a}$ (absolute humidity) as horizontal axes and $\tilde{w}$ (vertical velocity) as a vertical axis, which gave our four quadrants $\left(Q_{i}, i=1, \ldots, 4\right)$ as

$Q_{1}: \tilde{w}>0$ and $\tilde{T}>0$ or $\tilde{a}>0$ warm air rising or moist air rising, 


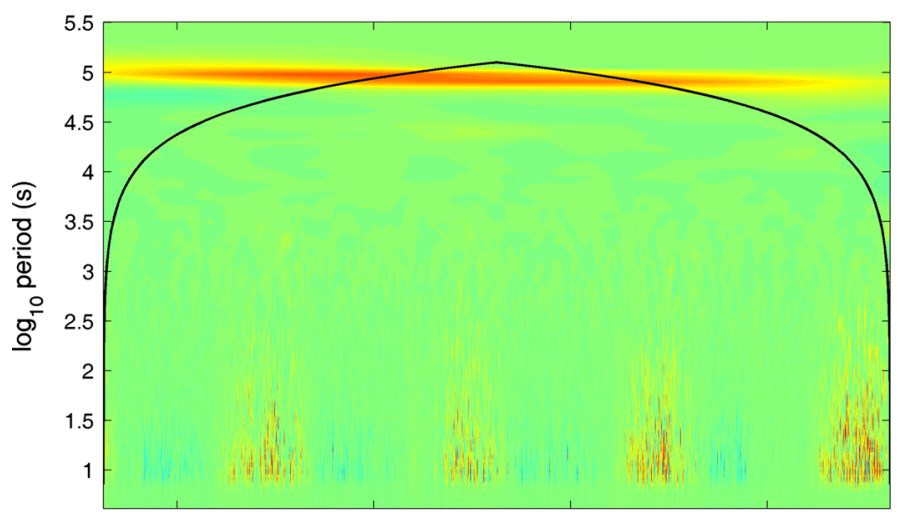

(a)

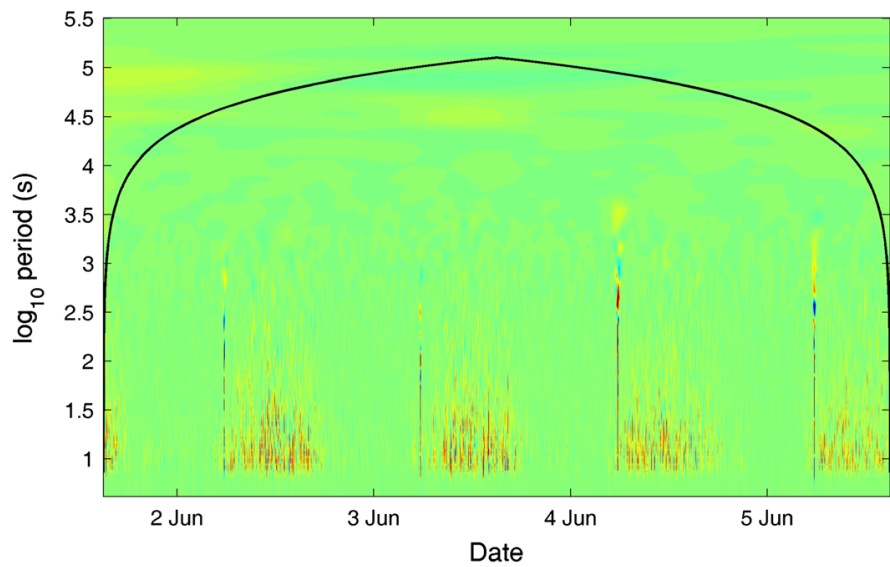

(b)

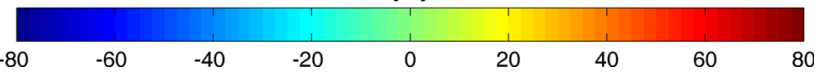

Fig. 5 Wavelet cross-scalograms over the rye field during 1 June 2003, 1500 UTC-5 June 2003, 1500 UTC of $\mathbf{a}$ sensible heat flux and $\mathbf{b}$ latent heat flux. The colour indicates values in $\mathrm{W} \mathrm{m}^{-2}$. The black solid line represents the cone of influence

$Q_{2}: \tilde{w}>0$ and $\tilde{T}<0$ or $\tilde{a}<0$ cold air rising or dry air rising,

$Q_{3}: \tilde{w}<0$ and $\tilde{T}<0$ or $\tilde{a}<0$ cold air sinking or dry air sinking,

$Q_{4}: \tilde{w}<0$ and $\tilde{T}>0$ or $\tilde{a}>0$ warm air sinking or moist air sinking.

$Q_{1}$ and $Q_{3}$ contribute to the positive flux, while $Q_{2}$ and $Q_{4}$ contribute to the negative flux. We then normalized each axis by its standard deviation and set the hyperbolic hole size to 0.5 $(H=0.5)$. We neglect the weak contributions inside the hole and only consider any points which satisfy

$$
\left|\frac{\tilde{w} \tilde{T}}{\sigma_{\tilde{w}} \sigma_{\tilde{T}}}\right| \text { or }\left|\frac{\tilde{w} \tilde{a}}{\sigma_{\tilde{w}} \sigma_{\tilde{a}}}\right|>H .
$$

With the quadrant analysis, we expect to see which types of turbulence actually contribute to the increasing or decreasing of $\tilde{w} \tilde{c}$. To make it consistent with our Hovmøller diagrams, we used the same observation period N P, which is 20 May 2003, 1200 UTC-18 June 2003, 


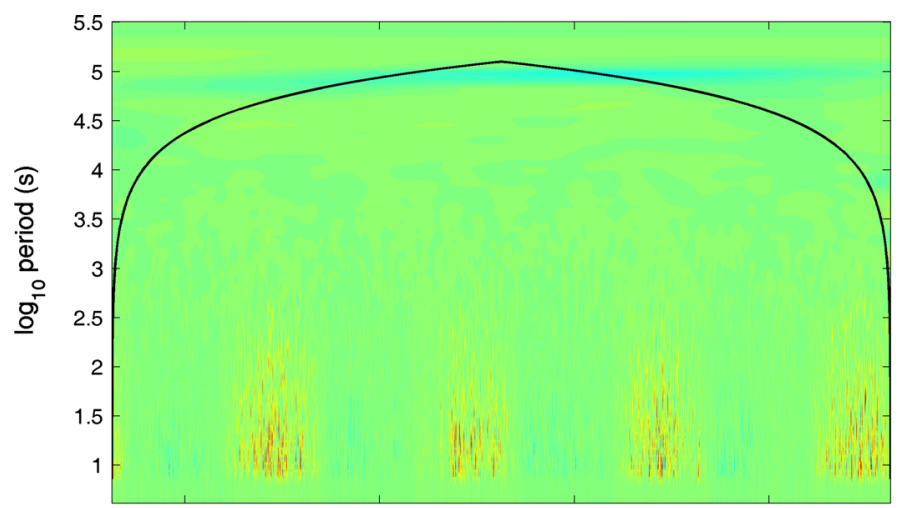

(a)

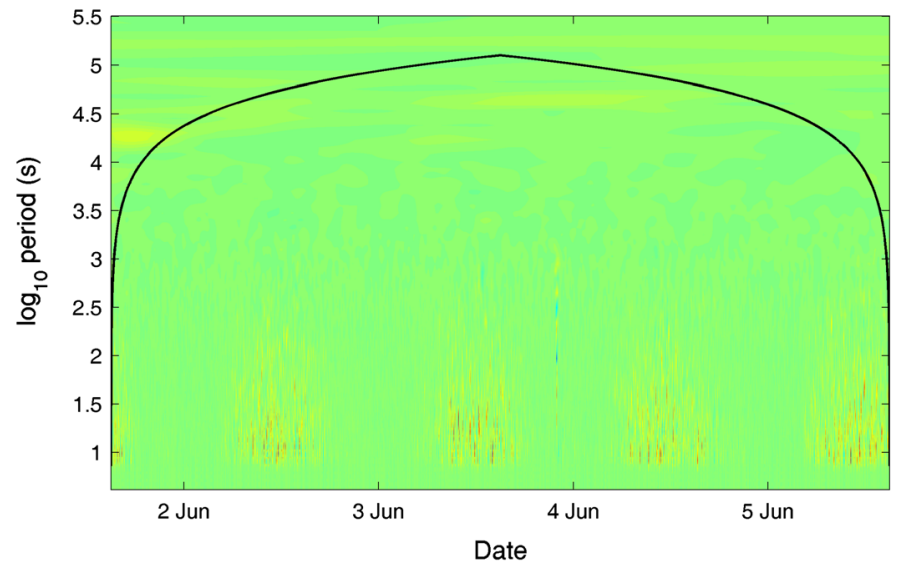

(b)

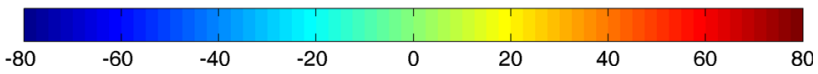

Fig. 6 Wavelet cross-scalograms over the grassland during 1 June 2003, 1500 UTC-5 June 2003, 1500 UTC of a sensible heat flux and $\mathbf{b}$ latent heat flux. The colour indicates values $\mathrm{W} \mathrm{m}^{-2}$. The black solid line represents the cone of influence

$0000 \mathrm{UTC}$, and set $P$ to $30 \mathrm{~min}$ (non-overlapped). Therefore, any points on the quadrant analysis diagram represent the normalized $\tilde{w} \tilde{c}$ from each non-overlapped 30-min period.

The results of the quadrant analysis of rye and grassland stations are shown in Fig. 7. In this figure, we used red dots to highlight all points obtained during 1 June 2003, 1500 UTC-5 June 2003, 1500 UTC. By considering only strong contributions outside a hyperbolic hole (blue line), we found that during this period, $\tilde{Q}_{\mathrm{H}}($ via $\tilde{w} \tilde{T})$ has a higher contribution from $Q_{1}$ (warm air rising) for the rye sites (Fig. 7a), while there is greater contribution from $Q_{4}$ (warm air sinking) for the grassland (Fig. 7b). There was no significant contribution outside the hyperbolic hole for $\tilde{Q}_{\mathrm{E}}$ (via $\tilde{w} \tilde{a}$ ) in both rye and grass stations. Over the maize field, the quadrant analysis is similar to that of the rye field, while the lake is similar to the grassland. For both rape and forest (not shown), $Q_{1}$ and $Q_{4}$ contributed equally to $\tilde{Q}_{\mathrm{H}}$, with no significant contribution outside the hole for $\tilde{Q}_{\mathrm{E}}$. These results tell us that the increase of $\left\langle Q_{\mathrm{H}}\right\rangle$ at larger $P$ at rye and maize fields was caused by warm air near the surface rising, while the decrease of $\left\langle Q_{\mathrm{H}}\right\rangle$ at grassland and lake was caused by warm air aloft sinking. For forest and rape stations, both contributions from $Q_{1}$ and $Q_{4}$ cancel each other and keep 

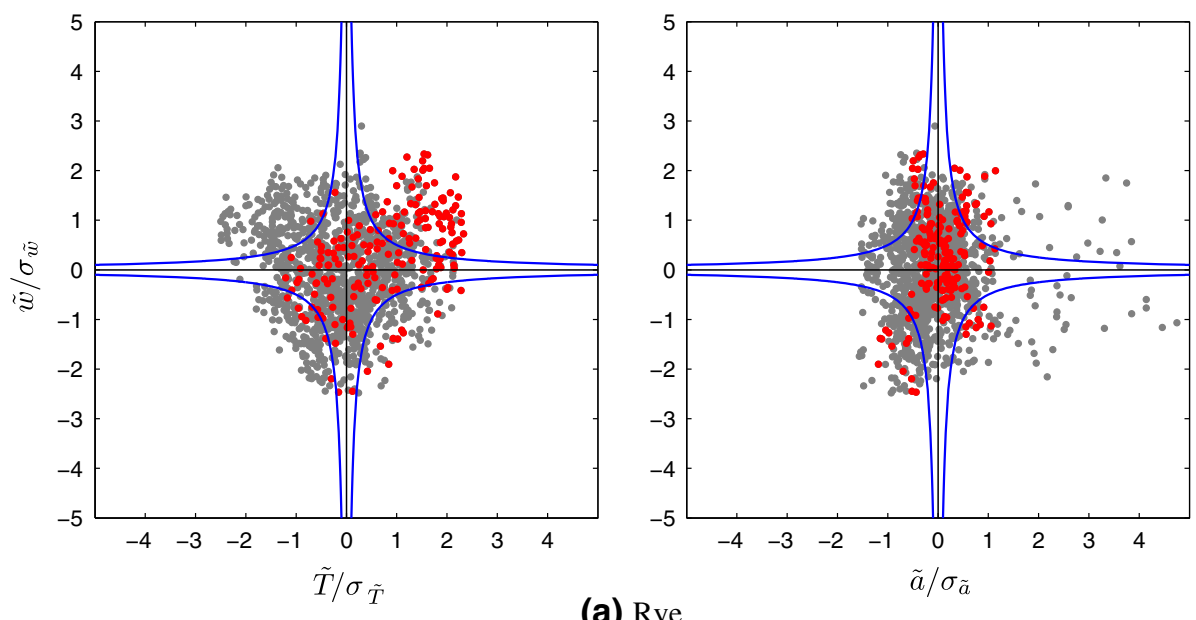

(a) Rye
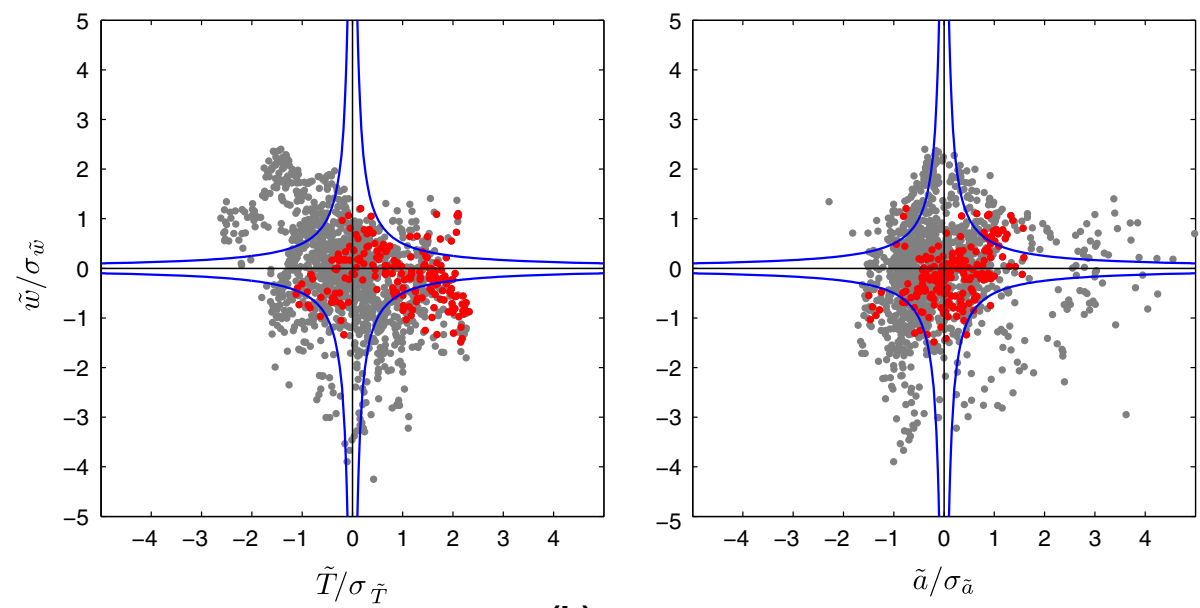

(b) Grassland

Fig. 7 Quadrant analysis of $\tilde{w} \tilde{T}$ (left panels represent the sensible heat flux) and $\tilde{w} \tilde{a}$ (right panels represent the latent heat flux) of a rye and b grass during 20 May 2003, 1200 UTC-18 June 2003, 0000 UTC. The period from 1 June 2003, 1500 UTC to 5 June 2003, 1500 UTC has been highlighted using red dots. The blue solid lines represent the hyperbolic hole $(H=0.5)$

$\left\langle Q_{\mathrm{H}}\right\rangle$ approximately constant at all $P$. The absence of significant contributions outside the hyperbolic hole keeps $\left\langle Q_{\mathrm{E}}\right\rangle$ approximately constant at all sites.

\section{Conclusions}

The modified ogive analysis, which requires steady-state conditions, reveals that extension of the averaging time by a few hours does not significantly improve the energy balance. The time extension has a greater impact over tall vegetation. Therefore, the 30 -min averaging time is still, overall, sufficient for the eddy-covariance calculation. Sensible heat flux, latent heat flux and $\mathrm{CO}_{2}$ flux are more sensitive to the time extension than is friction velocity. Over low vegetation, when the atmosphere becomes less stationary with greater averaging times, these 
three turbulent fluxes tend to increase. However, an increase in the degree of unsteadiness tends to decrease the $\mathrm{CO}_{2}$ flux. The increase of sensible heat flux is generally greater than the increase of latent heat flux. Over a longer period, the increases or decreases of sensible and latent heat fluxes do not always behave according to the scalar similarity as expected. And lastly, the sizes of the increases in both sensible and latent heat fluxes are not sufficient to close the energy balance at all sites.

Without assuming steady-state conditions, the block ensemble average can extend the averaging time to several days through the inclusion of the period-to-period fluctuations ( $\tilde{w} \tilde{c}, c$ is temperature or humidity) in the mean vertical flux. However, this does not usually close the energy balance. The Hovmøller diagram, which shows variations of $\tilde{w} \tilde{c}$ over a long period, can help to identify when secondary circulations exist in the vicinity of the sensor by exhibiting consecutive large $\tilde{w} \tilde{T}$. From our findings, secondary circulations that exist near the earth's surface mainly transport sensible heat. This result also supports the poor scalar similarity between the sensible and latent heat fluxes in the low frequency region (Ruppert et al. 2006; Foken et al. 2011).

Since secondary circulations move very slowly and are relatively large in size, a singletower EC measurement averaging over $30 \mathrm{~min}$ is unable to detect them. If the sensor is, coincidentally, at the right time and location when secondary circulations transport nearground warm air upwards, the block ensemble average at a longer period yields higher sensible heat flux, which improves the energy balance closure. However, when these near-surface secondary circulations transport warm air aloft downwards, the block ensemble average yields a lower sensible heat flux at a longer averaging time. This suggests that near-surface secondary circulations do transport significant amounts of energy, and these are responsible for the energy balance closure problem rather than sensor deficiencies.

To account for low frequency contributions to turbulent fluxes caused by near-surface secondary circulations, we must accept that the scalar similarity between the sensible and latent heat fluxes is no longer valid at all scales. Therefore, the widely used energy balance correction in Twine et al. (2000), EBC-Bo, which assumes the scalar similarity between sensible and latent heat fluxes by preserving the Bowen ratio, would not generally hold.

As we found that near-surface secondary circulations transport more sensible heat, the EBC-Bo correction may attribute less residual to the sensible heat flux than expected. Hence, we propose an alternative energy balance correction for a near-surface EC measurement through the buoyancy flux ratio (EBC-HB), in which convection plays a key role. The buoyancy flux, $Q_{\mathrm{B}}$, is defined as

$$
Q_{\mathrm{B}}=\rho c_{\mathrm{p}} \overline{w^{\prime} T_{\mathrm{v}}^{\prime}},
$$

where $\rho$ is the air density, $c_{\mathrm{p}}$ is the specific heat capacity of air at constant pressure, and $T_{\mathrm{v}}$ is the virtual temperature, which can be replaced by the sonic temperature $\left(T_{\mathrm{S}}\right)$ with negligible loss of accuracy (Kaimal and Gaynor 1991). This means that sonic anemometers can be used to directly measure $Q_{\mathrm{B}}$ with a good accuracy. The virtual temperature is related to the actual temperature $(T)$ and specific humidity $(q)$ in the same way as the sonic temperature (Schotanus et al. 1983), which leads to

$$
\begin{aligned}
Q_{\mathrm{B}}=\rho c_{\mathrm{p}} \overline{w^{\prime} T_{\mathrm{v}}^{\prime}} & =\rho c_{\mathrm{p}}\left(\overline{w^{\prime} T^{\prime}}+0.61 \bar{T} \overline{w^{\prime} q^{\prime}}\right) \\
& =Q_{\mathrm{H}}\left(1+0.61 \bar{T} \frac{c_{\mathrm{p}}}{\lambda B o}\right),
\end{aligned}
$$

where $\lambda$ is the heat of evaporation of water and $B o$ is the Bowen ratio. We next partition the residual via the buoyancy flux ratio, which contains both sensible and latent heat fluxes. The fraction of the residual attributed to the sensible heat flux depends on the relative contribution 


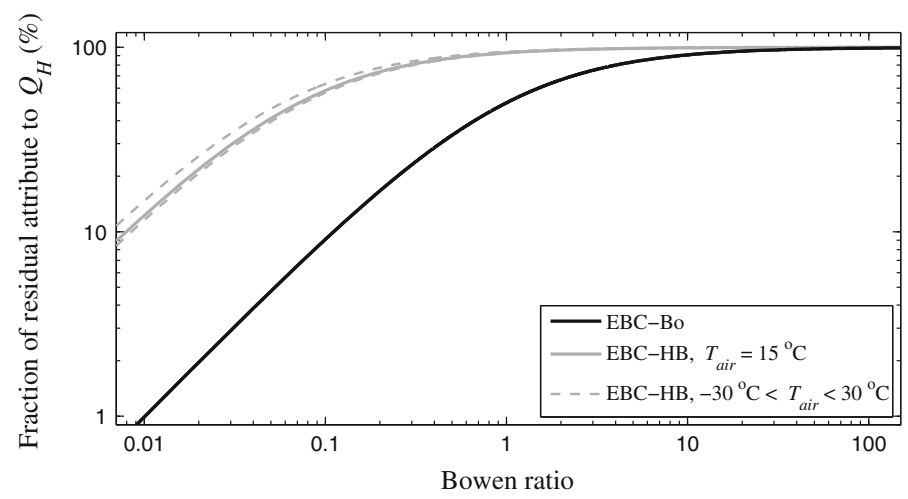

Fig. 8 Fraction of the residual attributed to the sensible heat flux at different Bowen ratios from two different approaches. The Bowen ratio approach (EBC-Bo, black line) assumes the scalar similarity between the sensible and latent heat fluxes by preserving the Bowen ratio (Twine et al. 2000). The buoyancy flux ratio approach (EBC-HB, grey lines) partitions the residual according to the ratio between the sensible heat flux and the buoyancy flux, and is shown at different temperatures from -30 to $30^{\circ} \mathrm{C}$. Although both approaches are identical at very large Bowen ratios, in most cases EBC-HB would attribute a larger fraction of the residual to the sensible heat flux than would EBC-Bo

of the sensible heat flux to the buoyancy flux. The remainder is then added to the latent heat flux. Therefore the corrected sensible and latent heat fluxes obtained with EBC-HB $\left(Q_{\mathrm{H}}^{\mathrm{EBC}-\mathrm{HB}}\right.$ and $Q_{\mathrm{E}}^{\mathrm{EBC}-\mathrm{HB}}$ respectively) are,

$$
\begin{aligned}
& Q_{\mathrm{H}}^{\mathrm{EBC}-\mathrm{HB}}=Q_{\mathrm{H}}+f_{\mathrm{HB}} \text { Res }, \\
& Q_{\mathrm{E}}^{\mathrm{EBC}-\mathrm{HB}}=Q_{\mathrm{E}}+\left(1-f_{\mathrm{HB}}\right) \text { Res },
\end{aligned}
$$

with

$$
f_{\mathrm{HB}}=\frac{Q_{\mathrm{H}}}{Q_{\mathrm{B}}}=\left(1+0.61 \bar{T} \frac{c_{\mathrm{p}}}{\lambda B o}\right)^{-1} .
$$

Since this method does not preserve the Bowen ratio, Eqs. 21-23 must be calculated iteratively until the Bowen ratio in Eq. 23 converges. The comparison between EBC-Bo and EBC-HB corrections is shown in Fig. 8. Both approaches are identical at very high Bowen ratios, i.e. all the residual is shifted to the sensible heat flux. For the typical range of the Bowen ratio, however, the EBC-HB correction would attribute more residual to the sensible heat flux than $\mathrm{EBC}-\mathrm{Bo}$ correction, which is more consistent with our findings.

Acknowledgments This research was funded by the German Research Foundation(DFG) within the projects FO 226/20-1 and BE 2044/4-1. The authors wish to thank all participants of the LITFASS-2003 experiment who produced data used in this analysis. All participants of the LITFASS-2003 experiment are listed in Beyrich and Mengelkamp (2006).

Open Access This article is distributed under the terms of the Creative Commons Attribution License which permits any use, distribution, and reproduction in any medium, provided the original author(s) and the source are credited.

\section{References}

Aubinet M, Vesala T, Papale D (eds) (2012) Eddy covariance: a practical guide to measurement and data analysis. Springer, Dordrecht, 438 pp. 
Bernstein AB (1966) Examination of certain terms appearing in Reynolds' equations under unsteady conditions and their implications for micrometeorology. Q J R Meteorol Soc 92:533-542

Bernstein AB (1970) The calculation of turbulent fluxes in unsteady conditions. Q J R Meteorol Soc 96:762762

Beyrich F, Mengelkamp HT (2006) Evaporation over a heterogeneous land surface: EVA_GRIPS and the LITFASS-2003 experiment-an overview. Boundary-Layer Meteorol 121:5-32

Beyrich F, Leps JP, Mauder M, Bange J, Foken T, Huneke S, Lohse H, Lüdi A, Meijninger WML, Mironov D, Weisensee U, Zittel P (2006) Area-averaged surface fluxes over the LITFASS region based on eddycovariance measurements. Boundary-Layer Meteorol 121:33-66

de Feriet JK (1951) Average processes and Reynolds equations in atmospheric turbulence. J Meteorol 8:358361

Desjardins RL, MacPherson JI, Schuepp PH, Karanja F (1989) An evaluation of aircraft flux measurements of $\mathrm{CO}_{2}$, water vapor and sensible heat. Boundary-Layer Meteorol 47:55-69

Eigenmann R, Metzger S, Foken T (2009) Generation of free convection due to changes of the local circulation system. Atmos Chem Phys 9:8587-8600

Finnigan JJ, Clement R, Malhi Y, Leuning R, Cleugh H (2003) A re-evaluation of long-term flux measurement techniques part I: averaging and coordinate rotation. Boundary-Layer Meteorol 107:1-48

Foken T (2008a) The energy balance closure problem: an overview. Ecol Appl 18:1351-1367

Foken T (2008b) Micrometeorology. Springer, Berlin 308 pp

Foken T, Wichura B (1996) Tools for quality assessment of surface-based flux measurements. Agric For Meteorol 78:83-105

Foken T, Göckede M, Mauder M, Mahrt L, Amiro B, Munger W (2004) Post-field data quality control. In: Lee X, Massman W, Law B (eds) Handbook of micrometeorology: a guide for surface flux measurement and analysis. Kluwer, Dordrecht, pp 181-208

Foken T, Wimmer F, Mauder M, Thomas C, Liebethal C (2006) Some aspects of the energy balance closure problem. Atmos Chem Phys 6:4395-4402

Foken T, Mauder M, Liebethal C, Wimmer F, Beyrich F, Leps JP, Raasch S, DeBruin H, Meijninger W, Bange J (2010) Energy balance closure for the LITFASS-2003 experiment. Theor Appl Climatol 101:149-160

Foken T, Aubinet M, Finnigan JJ, Leclerc MY, Mauder M, Paw UKT (2011) Results of a panel discussion about the energy balance closure correction for trace gases. Bull Am Meteorol Soc ES92:13-ES18.

Foken T, Leuning R, Oncley SR, Mauder M, Aubinet M (2012) Corrections and data quality control. In: Aubinet M, Vesala T, Papale D (eds) Eddy covariance. Springer, Berlin, pp 85-131

Haverd V, Cuntz M, Leuning R, Keith H (2007) Air and biomass heat storage fluxes in a forest canopy: calculation within a soil vegetation atmosphere transfer model. Agric For Meteorol 147:125-139

Hollinger DY, Richardson AD (2005) Uncertainty in eddy covariance measurements and its application to physiological models. Tree Physiol 25:873-885

Inagaki A, Letzel MO, Raasch S, Kanda M (2006) Impact of surface heterogeneity on energy imbalance: a study using LES. J Meteorol Soc Jpn 84:187-198

Kaimal JC, Finnigan JJ (1994) Atmospheric boundary layer flows: their structure and measurement. Oxford University Press, Oxford 289 pp

Kaimal JC, Gaynor JE (1991) Another look at sonic thermometry. Boundary-Layer Meteorol 56:401-410

Kaimal JC, Wyngaard JC, Izumi Y, Cote OR (1972) Spectral characteristics of surface-layer turbulence. Q J R Meteorol Soc 98:563-589

Kanda M, Inagaki A, Letzel MO, Raasch S, Watanabe T (2004) LES study of the energy imbalance problem with eddy covariance fluxes. Boundary-Layer Meteorol 110:381-404

Leuning R, van Gorsel E, Massman WJ, Isaac PR (2012) Reflections on the surface energy imbalance problem. Agric For Meteorol 156:65-74

Liebethal C, Huwe B, Foken T (2005) Sensitivity analysis for two ground heat flux calculation approaches. Agric For Meteorol 132:253-262

Lindroth A, Mölder M, Lagergren F (2010) Heat storage in forest biomass improves energy balance closure. Biogeosciences 7:301-313

Liu H, Peters G, Foken T (2001) New equations for sonic temperature variance and buoyancy heat flux with an omnidirectional sonic anemometer. Boundary-Layer Meteorol 100:459-468

Massman WJ, Lee X (2002) Eddy covariance flux corrections and uncertainties in long-term studies of carbon and energy exchanges. Agric For Meteorol 113:121-144

Mauder M, Foken T (2004) Documentation and instruction manual of the eddy covariance software package TK2. Work Report University of Bayreuth, Department of Micrometeorology, ISSN 1614-8916, 26, 42 pp.

Mauder M, Foken T (2006) Impact of post-field data processing on eddy covariance flux estimates and energy balance closure. Meteorol Z 15:597-609 
Mauder M, Liebethal C, Göckede M, Leps JP, Beyrich F, Foken T (2006) Processing and quality control of flux data during LITFASS-2003. Boundary-Layer Meteorol 121:67-88

Mauder M, Desjardins RL, Oncley SP, MacPherson I (2007) Atmospheric response to a partial solar eclipse over a cotton field in central california. J Appl Meteorol Climatol 46:1792-1803

Mauder M, Foken T, Clement R, Elbers JA, Eugster W, Grünwald T, Heusinkveld B, Kolle O (2008) Quality control of CarboEurope flux data-part 2: inter-comparison of eddy-covariance software. Biogeosciences 5:451-462

Meek DW, Prueger JH, Kustas WP, Hatfield JL (2005) Determining meaningful differences for SMACEX eddy covariance measurements. J Hydrometeorol 6:805-811

Meyers TP, Hollinger SE (2004) An assessment of storage terms in the surface energy balance of maize and soybean. Agric For Meteorol 125:105-115

Moore CJ (1986) Frequency response corrections for eddy correlation systems. Boundary-Layer Meteorol $37: 17-35$

Nakamura R, Mahrt L (2006) Vertically integrated sensible heat budgets for stable nocturnal boundary layers. Q J R Meteorol Soc 132:383-403

Oncley SP, Businger JA, Itsweire EC, Friehe CA, C LJ, Chang SS (1990) Surface layer profiles and turbulence measurements over uniform land under near-neutral conditions. In: 9th symposium on boundary layer and turbulence. American Meteorological Society, Roskilde pp 237-240.

Oncley SP, Foken T, Vogt R, Kohsiek W, DeBruin HAR, Bernhofer C, Christen A, van Gorsel E, Grantz D, Feigenwinter C, Lehner I, Liebethal C, Liu H, Mauder M, Pitacco A, Ribeiro L, Weidinger T (2007) The energy balance experiment EBEX-2000. Part I: overview and energy balance. Boundary-Layer Meteorol 123:1-28

Paw UKT, Baldocchi DD, Meyers TP, Wilson KB (2000) Correction of eddy-covariance measurements incorporating both advective effects and density fluxes. Boundary-Layer Meteorol 97:487-511

Raabe A (1983) On the relation between the drag coefficient and fetch above the sea in the case of off-shore wind in the near-shore zone. Z Meteorol 33:363-367

Ruppert J, Thomas C, Foken T (2006) Scalar similarity for relaxed eddy accumulation methods. BoundaryLayer Meteorol 120:39-63

Schotanus P, Nieuwstadt F, De Bruin H (1983) Temperature measurement with a sonic anemometer and its application to heat and moisture fluxes. Boundary-Layer Meteorol 26:81-93

Shaw RH (1985) On diffusive and dispersive fluxes in forest canopies. In: Hutchinson BA, Hicks BB (eds) The forest-atmosphere interaction. Reidel Publishing Company, Dordrecht, pp 407-419

Steinfeld G, Letzel M, Raasch S, Kanda M, Inagaki A (2007) Spatial representativeness of single tower measurements and the imbalance problem with eddy-covariance fluxes: results of a large-eddy simulation study. Boundary-Layer Meteorol 123:77-98

Stoy PC, Mauder M, Foken T, Marcolla B, Boegh E, Ibrom A, Arain MA, Arneth A, Aurela M, Bernhofer C, Cescatti A, Dellwik E, Duce P, Gianelle D, van Gorsel E, Kiely G, Knohl A, Margolis H, McCaughey H, Merbold L, Montagnani L, Papale D, Reichstein M, Saunders M, Serrano-Ortiz P, Sottocornola M, Spano D, Vaccari F, Varlagin A (2013) A data-driven analysis of energy balance closure across fluxnet research sites: the role of landscape scale heterogeneity. Agric For Meteorol 171-172:137-152

Tanner BD, Swiatek E, Greene JP (1993) Density fluctuations and use of the krypton hygrometer in surface flux measurements. In: Allen RG (ed) Management of irrigation and drainage systems: integrated perspectives. American Society of Civil Engineers, New York, pp 945-952

Torrence C, Compo GP (1998) A practical guide to wavelet analysis. Bull Am Meteorol Soc 79:61-78

Twine TE, Kustas WP, Norman JM, Cook DR, Houser PR, Meyers TP, Prueger JH, Starks PJ, Wesely ML (2000) Correcting eddy-covariance flux underestimates over a grassland. Agric For Meteorol 103:279-300

Webb EK, Pearman GI, Leuning R (1980) Correction of flux measurements for density effects due to heat and water vapour transfer. Q J R Meteorol Soc 106:85-100

Wilczak J, Oncley S, Stage S (2001) Sonic anemometer tilt correction algorithms. Boundary-Layer Meteorol 99:127-150 